\title{
Information (Non)Aggregation in Markets with Costly Signal Acquisition
}

\author{
Brice Corgnet \\ EM Lyon Business \\ School, GATE ${ }^{+}$ \\ Cary Deck \\ Mark DeSantis* \\ David Porter \\ University of \\ Alabama $^{\ddagger}$ \\ Chapman University ${ }^{\Delta}$ \\ Chapman University ${ }^{\Delta}$ \\ Chapman University ${ }^{\Delta}$
}

October 2017

Markets are often viewed as a tool for aggregating disparate private knowledge, a stance supported by past laboratory experiments. However, traders' acquisition cost of information has typically been ignored. Results from a laboratory experiment involving six treatments varying the cost of acquiring signals of an asset's value suggest that when information is costly, markets do not succeed in aggregating it. At an individual level, having information improves trading performance, but not enough to offset the cost of obtaining the information. Although males earn more through trading than females, this differential is offset by the greater propensity of males to buy information such that total profit is similar for males and females. Looking at individual skills, we find that higher theory of mind is associated with greater trading profit, greater overall profit, and an increased likelihood of acquiring information while cognitive reflection is associated with greater profit but not a greater propensity to acquire information.

Key Words: Prediction Markets, Information Acquisition, Laboratory Experiments, Behavioral Finance

JEL Codes: C9, D8, G1

* Corresponding author: Mark DeSantis, desantis@chapman.edu, 714.997.6957

Institution addresses:

† 23 Avenue Guy de Collongue, 69130 Écully

${ }^{\ddagger} 261$ Stadium Drive, Tuscaloosa, AL 35487

${ }^{\Delta}$ One University Drive, Orange, CA 92866

Acknowledgements: The authors wish to thank participants at the Chapman University Conference in Honor of Vernon Smith and the Chapman University Conference on the Experimental and Behavioral Aspects of Financial Markets for helpful comments. Support for this project was provided by the University of Arkansas through the Bank of America James H. Penick Research Grant for Banking and Finance program. Brice Corgnet acknowledges the continuous support of the Economic Science Institute at Chapman University as well as LABEX CORTEX (Univ. Lyon). 


\section{Introduction}

The notion that markets aggregate private information has been put forward since Hayek (1945) and Muth (1961), but it was Plott and Sunder (1988) who introduced the canonical experimental market for studying such a phenomenon. ${ }^{1}$ The experimental results in their paper suggest that markets do aggregate individual traders' disparate information. Since the publication of those early results, there has been considerable attention given to the predictions such markets can yield both in and out of the laboratory.

With respect to field studies, while Chen and Plott (2002) and Gillen et al. (2017) discuss the successful use of prediction markets at Hewlett-Packard and Intel, respectively, firms such as Google, Microsoft, Yahoo, and IBM also make use of internal markets for aggregating information (see Cowgill et al. 2008). Pennock et al. (2001) documents the ability of the Hollywood Stock Exchange to forecast the success of yet to be released movies, and Berg et al. (2003) documents the success of the lowa Electronic Market for predicting the outcomes of US elections. ${ }^{2}$ In fact, the evidence of markets aggregating information is sufficiently strong that a large group of scientists called for the relaxation of various laws to facilitate greater use of prediction markets (see Arrow et al. 2008).

Deck and Porter (2013) provides a recent survey of the experimental evidence for information aggregation. Much of this previous experimental work has either explicitly assumed that traders are endowed with information or implicitly assumed that individual traders have collected information in the course of their normal activities. These are non-trivial assumptions. If markets are completely efficient so that prices fully reflect all information held by traders, then one would never incur a cost to acquire new information solely for the purpose of trading as the cost of the information could not be recovered (Grossman and Stiglitz, 1980). The implication is that no trader would seek out costly information and thus such information could not be reflected in the price. The costly collection of information requires that markets either do not fully reflect all available information or only do so gradually. ${ }^{3}$

The experimental literature directly exploring the effect of costly information acquisition on market aggregation is limited to a few studies. This literature includes the seminal papers of Sunder (1992) and Copeland and Friedman (1992) as well as the more recent works of Huber et al. (2011), Page and Siemroth (2017), and Asparouhova et al. (2017). Sunder (1992) introduces information cost in two ways. One is to auction off information to the highest bidder. With repetition, the price of information falls toward zero, and this information is reflected in the

\footnotetext{
${ }^{1}$ Plott and Sunder (1982) has a similar structure, but investigates information dissemination (some traders are fully informed of the asset's true value, while others are uninformed) rather than aggregation (all traders are partially informed of the asset's true value). Information dissemination is also sometimes referred to as information amplification (e.g. Bossaerts et al. 2014).

${ }^{2}$ The success is not universal (see e.g. Jacobsen et al. 2000 and Brüggelambert 2004; Corgnet et al. 2015; Camerer et al. 2016).

${ }^{3}$ Hanson and Oprea (2009) show theoretically that traders would still acquire costly information in the presence of a market manipulator.
} 
price of the underlying asset. The findings of Copeland and Friedman (1992) are consistent with Sunder (1992). While this approach fixes the amount of information in a market, Sunder's other approach, which enables any trader to purchase information at a fixed price, is arguably more directly related to the various prediction markets described above. In this setting, Sunder reports that markets do not fully aggregate information (i.e., the prices do not reflect the true asset value) and that those traders who do buy information are able to recoup their investment. While Sunder's results are suggestive, they are based on only six sessions that differ from each other in several potentially important ways including the process determining asset value, the price of information, and the experience level of the subjects. Page and Siemroth (2017) extends Sunder (1992) by studying the effect of both traders' endowments and traders' information heterogeneity on information acquisition, but in an environment with a different information structure. Whereas Sunder (1992) consider the case of aggregate certainty in which the collection of all private signals in the market determines the value of the asset with certainty, Page and Siemroth (2017) study the case of aggregate uncertainty using the ball-and-urn setup developed by Anderson and Holt (1997). In that case, all private signals available in the market do not determine the value of the asset with certainty. Under this procedure, signals which are obtained by observing the color of a ball drawn from a two-color urn can never be fully revealing about the actual state of the world because draws are made with replacement. Using experimental markets and theoretical models respectively, Lundholm (1991) and Chen et al. (2006) argue that aggregate uncertainty precludes information aggregation. The findings of Page and Siemroth (2017) regarding the limited evidence for information aggregation are thus consistent with Lundholm (1991) and Chen et al. (2006). In addition to a baseline, Page and Siemroth (2017) designed a public draw treatment in which all traders received the same noisy public signal before deciding whether to acquire further information. The treatment was compared to the baseline in which the initial traders' information was privately held. The authors also considered a second treatment (high endowment) in which traders vary in their level of endowment so that half of the traders in the market had a level of cash and shares which was twice higher than in the baseline. In line with their conjectures, the authors show that traders are more likely to acquire information in the public draw treatment than in the baseline. Also, traders who received more cash and shares in the high endowment treatment acquired more information than the remaining traders.

Huber et al. (2011) also extend the work of Sunder (1992) by considering the case in which traders can bid to become a (possibly fully) informed trader at an early period in the experiment following the design of Huber (2007) and Kirchler (2010). The authors consider a total of five different information levels which differ in the exact timing in which a trader learns the true value of the asset. In their fixed cost treatments, they consider different values for the cost of being informed early. ${ }^{4}$ For each treatment, they only impose that the cost of being informed at an earlier period is lower than the cost of being informed at a later period. In line

\footnotetext{
${ }^{4}$ The authors also consider treatments in which information is priced using a Vickrey auction.
} 
with Page and Siemroth (2007), they find that informed traders' earnings (net of the cost of information) is lower than uninformed traders' earnings. They also show that an increase in the cost of information significantly decrease the likelihood of traders to purchase information. Finally, they show that an increase in the cost of information led to a decrease in the informational efficiency of markets.

All previous experimental works studied information acquisition in a centralized double auction market. Instead, Asparouhova et al. (2017) assess the extent to which traders acquire costly information in a decentralized setting following the theoretical framework of Duffie, Malamud and Manso (2014). In that setup, which aims at mimicking over-the-counter markets, traders take either the role of buyers or sellers. Asparouhova et al. (2017) show both theoretically and experimentally that the argument by which traders will be deterred to acquire costly information because prices reflect all available information does not hold in a decentralized market (Grossman and Stiglitz, 1980). Instead, traders are willing to acquire costly information because prices do not perfectly reflect all available information.

This paper provides a systematic examination of information aggregation in centralized markets in which traders can obtain costly signals of an asset's value. It complements the work of Page and Siemroth (2017) by varying the number and the cost of the signals instead of focusing on institutional factors and by considering the case of aggregate certainty in line with the previous works of Plott and Sunder (1988) and Sunder (1992). Our work also complements Huber et al. (2011) by considering a case in which traders pay for acquiring a signal, as in Sunder (1992), rather than for knowing the true value of the asset at an earlier date. We also extend previous works by assessing the effect of making information acquisition decisions commonly known to all traders at the beginning of each market. Finally, we extend previous studies by inquiring on the cognitive drivers of information acquisition and traders' profits.

Using a total of six different treatments and 240 subjects, our findings show, in line with Huber et al. (2011) and Page and Siemroth (2017), that traders, especially males, acquire an excessive number of signals thus harming their trading profits. In addition, our finding regarding the negative effect of knowing others' information purchasing decisions is of particular relevance. We are not aware of a similar finding in the experimental literature. This result suggests that the advent of new technologies of information may have had two countervailing effects. On the one hand, information may have become less costly thanks to greater competition between news and data providers. On the other hand, social networks and other web-based communication technologies may have made traders more aware of others' information acquisition strategies thus reducing the appeal for information purchasing. Following Corgnet et al. (2017), we also extend previous works by assessing the role of cognitive factors such as theory of mind skills and cognitive reflection in understanding individual decisions to acquire information. We find that theory of mind is associated with greater trading profit, greater overall profit, and an increased likelihood of acquiring information while cognitive reflection is associated with greater profit but not a greater propensity to acquire information. The fact 
that both cognitive reflection and theory of mind positively explain traders' earnings shows the robustness of the findings of Corgnet et al. (2017) to the case in which traders decide upon costly information acquisition.

\section{Experimental Design}

The experimental asset markets are similar to the ones in Plott and Sunder (1988) and Sunder (1992) in which eight subjects play the role of traders. ${ }^{5}$ In each of the ten market periods, every trader is endowed with e $\$ 1200$ and four asset shares, where e\$ represents the experimental currency. The experimental dollars were converted into US dollars at the rate e $\$ 1,000$ equals US\$1. At the start of a market period, traders were informed that the true value was equally likely to be e\$50, e\$240, or e\$490. Thus, a priori the expected value of an asset was e\$260. Traders could buy and sell assets using a computerized double auction. ${ }^{6}$ A market period lasted four minutes, after which the true value of the asset was revealed. Traders were informed of their payoff, which equaled their ending cash balance plus the realized value of any assets they held when the market closed. Cash and assets did not carry over from one market period to the next. Further, traders were not allowed to short shares or to borrow money. To reduce variation between treatments and among replications of the same treatment, a single set of asset value realizations was used in every session. This sequence was taken from Plott and Sunder (1988). ${ }^{7}$

In each market period every trader was endowed with an additional signal purchase budget of $\mathrm{e} \$ 600$. This money could be used before the market began to purchase information about the true value of the asset in the upcoming market period. A signal consisted of one or two clues. A clue informed the purchaser of one of the values that the asset did not take. For example, if the asset was worth $\mathrm{e} \$ 490$, a clue could be that the asset was not worth $\mathrm{e} \$ 50$. Depending upon the treatment, traders were able to buy either zero, one, or two signals. ${ }^{8}$ The e $\$ 600$ signal purchase budget could not be combined with the e\$1200 that the trader could use to buy assets in the market and unused signal purchase budget money was added to the subject's earnings at the end of the trading period. This important design feature differed from Huber et al. (2011) and Page and Siemroth (2017). ${ }^{9}$ Keeping the signal purchase budget separate ensures

\footnotetext{
${ }^{5}$ In both Plott and Sunder (1988) and Sunder (1992), only a single experimental session was run under each of several treatments that varied widely, making specific conclusions about any particular design feature problematic (see Corgnet et al. 2015).

${ }^{6}$ The experiment was conducted using Zocalo which is an open-source software used for experimental markets.

${ }^{7}$ The realized states are taken from Market 9 of Plott and Sunder (1998). Periods 1-5 correspond to the first five periods in that session while periods 6-10 correspond to the last 5 periods in that session.

${ }^{8}$ When a trader receives a single signal consisting of one clue, that clue is randomly determined. Continuing the example, if the asset was worth $\mathrm{e} \$ 490$, a trader was equally likely to be informed that the asset was not worth $\mathrm{e} \$ 50$ or that it was not worth e $\$ 240$. A trader who received a signal that the asset was not worth e\$50 would expect the asset to be worth e $\$ 365$ since, conditional on the trader's information, the asset was equally likely to be worth e $\$ 240$ or e $\$ 490$

${ }^{9}$ This design feature is not relevant for Sunder (1992) as subjects can borrow money so that there are no liquidity constraints.
} 
that the total liquidity in the asset market remains fixed regardless of the total amount of information acquired by traders and eliminates a liquidity penalty to traders who do acquire information.

To examine the effects of costly information acquisition, we collected data from six different treatments.

In the Baseline, a signal consisting of a single clue costs e $\$ 300$ and each trader could purchase up to one signal. The clue cost in the Baseline was chosen to be near the maximum possible expected value of a clue. The maximum value of information is obtained when prices do not reveal any private information. In that situation, the value of a clue is maximal when only one of the traders acquires information. To calculate this value, we consider the expected gains associated to purchasing one signal given the specific clue received. Suppose the trader received the clue "Not 50." Given this signal, the trader would calculate the expected value of the asset to be $\mathrm{e} \$ 365=\frac{1}{2} \times \mathrm{e} \$ 240+\frac{1}{2} \times \mathrm{e} \$ 490$. The remaining traders who did not purchase a signal would value the asset at e\$260. Given the initial cash endowment of $e \$ 1,200$, in this scenario the trader who received the signal would purchase four assets at the price of e\$260 per asset. The trader's expected trading profit would then be e\$3,080 =e $\$ 1,200+8 \times \mathrm{e} \$ 365-$ $4 \times$ e\$260. If the trader received the clue "Not 240," then she would calculate the expected value of the asset to be e\$270. Similar to the above scenario, this trader would purchase four assets at the price of e\$260 per asset, and her expected trading profit would be e $\$ 2,320$. Finally, suppose the trader received the clue "Not 490." In this case she would calculate an expected value of e\$145 and therefore sell her endowment of four assets for e\$260 each. Thus, her expected trading profit would be e $\$ 2,240=\mathrm{e} \$ 1,200+4 \times \mathrm{e} \$ 260$. Thus, a priori the expected trading profit of a trader who buys a signal when no other trader does is $\$ 2,546.7$ since each clue is equally likely. The maximum value of a single signal consisting of one clue may be determined by subtracting the expected value of the initial portfolio $(e \$ 2,240=$ e\$1,200+4 x e\$260) from e\$2,546.7 giving e\$306.7. We then round to e\$300 for the signal cost in the Baseline. By comparison, the minimum possible value of a clue is zero which corresponds to the case in which prices fully reveal private information.

In the Baseline, traders were not informed of the information purchase decisions of the other traders as in Huber et al. (2011) or Page and Siemroth (2017).

The High Cost treatment was similar to the Baseline except that a signal costs e\$600. This cost per signal is approximately double the maximum value of a clue thus ensuring that the acquisition of information would reduce a trader's earnings.

The Precise treatment was similar to the Baseline except that, for the same price, a single signal contained two different clues. Thus, the e\$150 cost per clue was lowest in the Precise treatment, and any trader who purchased a signal was fully informed. In this case the maximum value of a signal, e $\$ 613.3$, was substantially higher than the e $\$ 300$ signal cost. Thus, 
in the absence of fully-revealing prices we would expect this treatment to lead to the greatest amount of information acquired by traders.

In the Full Information treatment, each trader could purchase up to two signals with each containing a single clue and costing e\$300. When a trader purchased two signals then the trader was fully informed of the actual asset value as the second signal would not be the same as the first signal. In that case, the total cost of acquiring the two signals (e\$600) and thus being fully informed is set to be approximately equal to the maximum value of being fully informed (e\$613.3). Similar to the case of one single clue, the maximum value of acquiring two clues was calculated for the case in which no other trader purchases information and markets do not reflect private information.

The Distribution treatment was similar to the Baseline except that traders were informed of the total number of signals purchased and thus the total amount of information in the market. This was implemented by writing the number of signals purchased on the board at the front of the lab after traders made their signal purchase decision but before trading began. ${ }^{10} \mathrm{~A}$ similar treatment was conducted in two market sessions in Sunder (1992). However, the insufficient number of sessions did not allow for a statistically meaningful comparison across treatments so that this treatment manipulation did not lead to any of the eight main findings reported by Sunder (1992).

The final treatment, referred to as No Information, did not allow traders to purchase any signals although they did still receive the e $\$ 600$ signal purchase budget to be consistent with the other treatments. This treatment allows us to measure the extent to which the markets in which costly acquisition of information is allowed can improve the informational efficiency of markets in which no private information is available. In the extreme case in which no trader ever purchased any information all six treatments should yield the same behavior and expected payoff. The six treatments are summarized in Table 1 . Note that each treatment deviates in only one respect from the Baseline treatment.

\footnotetext{
${ }^{10}$ Sunder (1992) varied whether or not traders were informed of how many traders purchased information.
} 
Table 1 Summary of Experimental Treatments

\begin{tabular}{lcccccc}
\hline \hline & Full & Figh & No \\
Signal Purchasing & Precise & $\begin{array}{c}\text { Full } \\
\text { Information }\end{array}$ & Distribution & $\begin{array}{c}\text { Cost } \\
\text { Information }\end{array}$ \\
\cline { 2 - 7 } Signal Purchase Budget & 600 & 600 & 600 & 600 & 600 & 600 \\
Maximum Signals Trader Could Purchase & 1 & 1 & 2 & 1 & 1 & 0 \\
Cost per Signal & 300 & 300 & 300 & 300 & 600 & - \\
Clues per Signal & 1 & 2 & 1 & 1 & 1 & - \\
Revelation of Number of Clues Purchased & No & No & No & Yes & No & No $^{\text {a }}$ \\
Market Characteristics & & & & & & \\
Number of Traders & 8 & 8 & 8 & 8 & 8 & 8 \\
Cash & 1200 & 1200 & 1200 & 1200 & 1200 & 1200 \\
Shares & 4 & 4 & 4 & 4 & 4 & 4 \\
\hline
\end{tabular}

${ }^{a}$ In this case it was common information that no one could purchase a signal, but this was not emphasized in the same manner that the number of purchased signals was in Distribution.

In every treatment, other than No Information, the total number of signals held by traders is endogenous. For treatments in which the number of clues per signal was one, if the number of signals purchased was even, then the experimental software ensured that information was balanced in the market with half of those purchasing a single signal given one possible clue and the other half given the other possible clue. For example, if six people purchased one signal and the true asset value was e $\$ 240$ then three people would be given the clue that the true value was not e $\$ 50$ and three would be given the clue that the true value was not e $\$ 490$. If the number of signals purchased was odd, then the market was as balanced as possible.

A total of 30 experimental sessions were conducted, five for each treatment. In each session eight subjects entered the laboratory and were seated at isolated workstations. The subjects read computerized instructions specific to the assigned treatment and answered a series of comprehension questions. The comprehension questions and the text of the subject instruction for the Baseline are available in Appendix A. The subjects then participated in a practice market that was similar in every way to the main part of the experiment except that earnings in the practice market did not impact a subject's payment. The main experiment lasted for 10 market periods after which subjects completed a short survey, were paid their earnings in private, and were dismissed from the experiment.

Our short survey elicited traits in addition to basic demographic questions. In particular, we elicited cognitive reflection and theory of mind because trader earnings in experimental markets have been shown to positively relate to these two measures (see Corgnet et al. 2017; Hefti et al. 2016). We used the seven-item cognitive reflection test (CRT) of Toplak et al. (2014), which is an expanded version of the three-question test by Frederick (2005). These questions are designed to have an intuitive but wrong answer and thus can measure how deeply subjects are thinking about their responses. The CRT is commonly used in laboratory experiments and has been found to predict who will fall prey to a variety of behavioral biases (see Oechssler et al. 2009; Toplak et al. 2011; 2014). Noussair et al. (2014) and Corgnet et al. (2015; 2017) show 
that CRT score (i.e., the number of correct responses on the CRT) predicts earnings in experimental asset markets. For theory of mind (ToM), we used the eye-gaze test of BaronCohen et al. (1997). In this task respondents try to identify a person's emotional state from a picture that reveals only the eyes and the bridge of the nose. This test is designed to measure how well someone can infer the intentions of others. Bruguier et al. (2010) report that traders who score well on the ToM test are better able to predict price changes in experimental asset markets with insiders. Corgnet et al. (2017) and Hefti et al. (2016) also find that those who score well on this test are better able to glean insights from market orders (bids, asks, and prices). Subjects were paid US\$3 for completing the survey, though none of the individual tests were incentivized which is standard practice in the literature.

The experiments were conducted at the Economic Science Institute at Chapman University. Subjects were recruited for a 90-minute session and paid US\$7 for participating in addition to their salient earnings. No subject was allowed to participate in more than one session, and no subject had previously participated in any information aggregation or prediction market experiments at the lab. A subject's salient earnings were calculated as their cumulative earnings from the 10 market periods, including any unspent signal purchase budget. The average total payment was US\$36.80 (inclusive of the participation and survey completion payments).

\section{Conjectures}

Although no signals should be purchased if experimental markets are fully efficient, previous research has shown that, in a similar market design, asset prices are not fully informationally efficient (see Biais et al. 2005; Hanson, Oprea and Porter 2006; Veiga and Vorsatz 2010; Corgnet et al. 2015). Also, studies which have found supportive evidence for information aggregation have put forward the need for extensive learning (e.g. Forsythe and Lundholm, 1990; Choo et al. 2017). Using a different informational structure in which there is aggregate uncertainty Page and Siemroth (2017) also report that markets are not fully informationally efficient. Thus, in our experiments, we expect that signals will have a positive value as in Grossman and Stiglitz (1976) or Hauser et al. (2015).

Because of this we can expect traders to acquire information. Further, we expect more information to be acquired the greater the perceived benefit of information relative to its cost (see Grossman and Stiglitz, 1976 and Huber et al. 2001). Hence, when the cost of information is reduced or the precision of information is increased we anticipate traders buying more information. Additionally, providing feedback that others are acquiring information, which reduces the maximum benefit of acquiring information, will lead to less information being acquired.

We thus make the following main conjecture regarding information acquisition. 


\section{Conjecture I (Information Acquisition)}

i) Traders will purchase signals.

ii) The lower the cost of signals, the more signals traders will buy.

iii) Given a cost per signal, the more precise a signal, the more signals traders will buy.

iv) Knowing others' clue purchase decisions will lead traders to buy fewer signals.

Conjecture 1 leads to the following anticipated treatment effects. The High Cost and Distribution treatments will lead to less information acquisition than the Baseline whereas the Full Information and Precise treatments will lead to more information acquisition than the Baseline. Moreover, more information will be purchased in the Precise treatment than in the Full Information treatment, but no relative ordering is implied for High Cost and Distribution.

Because the treatments will differ in the amount of information held by traders, the degree to which market prices reflect the true asset value will also differ. As shown by Grossman and Stiglitz (1976) as well as Huber et al. (2011) and Bossaerts et al. (2014), a higher proportion of informed traders will lead to an increase in the informational efficiency of a market. This leads us to the following conjecture.

\section{Conjecture II (Informational Efficiency)}

i) We expect market prices to less accurately reflect true asset values in the High Cost and Distribution treatments than in the Baseline.

ii) We expect market prices to more accurately reflect true asset values in the Precise treatment than in the Full Information treatment and to more accurately reflect true asset values in the Full Information treatment than in the Baseline.

iii) We expect that market prices will not reflect true asset values in the No Information treatment, and we thus expect all other treatments to have greater informational efficiency than the No Information treatment.

At the individual level, we test the robustness of the results established by Hefti et al. (2016) and Corgnet et al. (2017) regarding the positive effect of cognitive skills on traders' earnings. Corgnet et al. (2017) show that cognitive reflection and theory of mind positively explain traders' earnings in experimental markets with private information similar to the ones used in the current design except for the fact that private signals were exogenously given to traders. Hefti et al. (2016) establish the robustness of these findings for the case in which markets are prone to bubbles and crashes (Smith et al. 1988). ${ }^{11}$ As is argued in Corgnet et al. (2017), cognitive reflection allows traders to reflect upon publicly available market orders to infer other traders' private information. Theory of mind is also key in performing well in markets with

\footnotetext{
${ }^{11}$ Both papers used the eye-gaze test to measure theory of minds skills. For cognitive reflection, Corgnet et al. (2017) used the CRT whereas Hefti et al. (2016) used performance on the game of Nim, which measures strategic sophistication.
} 
private information as it allows traders to identify whether prices are moved by informed or uninformed traders (see Bruguier et al. 2010). Based on previous research, we conjecture that the positive effect of cognitive reflection and theory of mind on traders' earnings will extend to the case in which information is acquired by traders instead of being exogenously given.

\section{Conjecture III (Traders earnings)}

Traders who possess higher cognitive reflection or higher theory of mind skills will achieve higher earnings.

\section{Results}

The data include the acquired information and market activity from 240 subjects in a total of 300 market periods. Table 2 provides summary information by treatment. With regard to personal characteristics of subjects across treatments there is no significant difference in gender composition, however CRT significantly differs between Full Information and No Information (t-test $\mathrm{p}$-value $=0.008$ ) and ToM significantly differs between Baseline and No Information (t-test $\mathrm{p}$-value $=0.034){ }^{12}$

Table 2 Summary of Data by Treatment

\begin{tabular}{|c|c|c|c|c|c|c|}
\hline & Baseline & $\begin{array}{c}\text { Full } \\
\text { Information }\end{array}$ & $\begin{array}{l}\text { High } \\
\text { Cost }\end{array}$ & Distribution & Precise & $\begin{array}{c}\text { No } \\
\text { Information }\end{array}$ \\
\hline $\begin{array}{l}\text { Average Number of } \\
\text { Purchased Clues }\end{array}$ & 4.76 & 6.20 & 3.00 & 3.32 & 8.84 & - \\
\hline $\begin{array}{l}\text { Average Trade Volume }{ }^{a} \\
\text { Average Transaction Price }^{b}\end{array}$ & 27.52 & 20.12 & 31.42 & 27.80 & 33.46 & 25.62 \\
\hline | Asset Value $=50$ & 191.51 & 126.02 & 191.88 & 171.64 & 111.74 & 242.17 \\
\hline | Asset Value $=240$ & 208.92 & 205.44 & 209.85 & 185.45 & 221.35 & 243.58 \\
\hline Asset Value $=490$ & 232.08 & 297.64 & 225.78 & 199.26 & 334.87 & 254.33 \\
\hline Average Absolute Price Error ${ }^{c}$ & 132.72 & 95.20 & 135.48 & 145.54 & 75.59 & 140.59 \\
\hline Percent Female & 60.00 & 60.00 & 57.50 & 57.50 & 60.00 & 62.50 \\
\hline Average CRT (out of 7) & 2.47 & 1.92 & 2.27 & 2.62 & 2.20 & 3.10 \\
\hline Average ToM (out of 36) & 25.45 & 25.72 & 25.62 & 26.12 & 25.52 & 27.07 \\
\hline
\end{tabular}

\subsection{Conjecture I. Information Acquisition}

We first compare the number of clues that traders acquire by treatment. The first column of Table 3 reports panel regression results with standard errors clustered at the session level. The results (and associated Wald tests shown in the lower portion of Table 3 ) indicate that more information is acquired in Full Information than in the other treatments except for Precise,

${ }^{12}$ All other pairwise t-test $p$-values $>0.05$. 
which has the most information acquisition. Both High Cost and Distribution lead to less information acquisition than the Baseline, but there is not a significant difference between the two treatments. ${ }^{13}$ Our findings thus support Conjecture 1 on information acquisition. The results also indicate that the amount of information purchased does not decline dramatically with experience. This is evidenced by the marginal significance of the coefficient of the Period variable, which assumes an integer value from one to ten. This finding is in line with what Page and Siemroth (2017) reported.

The right two columns of Table 3 compare the number of transactions across treatments. These regressions indicate that controlling for the number of signals traders acquire in a market period ("Signals" variable), there is no treatment difference in the number of transactions across treatments except that Full Information has marginally fewer trades. The results also indicate that with experience the number of transactions falls (the coefficient on Period is negative and significant). Finally, the results in the last column of Table 3 reveal that trade volume is not correlated with the underlying value of the asset, but it is inversely related to the number of signals acquired (the coefficient on Signals is negative and significant).

\footnotetext{
${ }^{13}$ The No Information treatment is excluded from specification [1] in Table 3 as there is no variation in the amount of information available. Mann Whitney tests indicate that in each of the five treatments where traders could acquire information, more information was acquired than in No Information (all pairwise $p$-values $<0.05$ ).
} 
Table 3 Regression Results for Information Acquisition and Transactions

\begin{tabular}{|c|c|c|c|}
\hline & $\begin{array}{c}\text { Number of Clues } \\
\text { Purchased } \\
{[1]}\end{array}$ & $\begin{array}{c}\text { Number of } \\
\text { Transactions } \\
\text { [2] }\end{array}$ & $\begin{array}{c}\text { Number of } \\
\text { Transactions } \\
\text { [3] }\end{array}$ \\
\hline \multirow[t]{2}{*}{ Constant } & $5.28 * * *$ & $36.08 * * *$ & $32.30 * * *$ \\
\hline & $(0.56)$ & $(4.73)$ & $(5.35)$ \\
\hline \multirow[t]{2}{*}{ Period } & $-0.09 *$ & $-1.56 * * *$ & $-1.45 * * *$ \\
\hline & $(0.05)$ & $(0.21)$ & (0.19) \\
\hline \multirow[t]{2}{*}{ Precise } & $4.08 * * *$ & 5.94 & 6.21 \\
\hline & $(0.91)$ & $(5.55)$ & $(5.74)$ \\
\hline \multirow[t]{2}{*}{ Full Information } & $1.44 *$ & -7.40 & $-8.56^{*}$ \\
\hline & $(0.75)$ & $(4.52)$ & (4.98) \\
\hline \multirow[t]{2}{*}{ Distribution } & $-1.44 * *$ & 0.28 & 1.44 \\
\hline & $(0.71)$ & (5.29) & $(5.88)$ \\
\hline \multirow[t]{2}{*}{ High Cost } & $-1.76 * * *$ & 3.90 & 5.31 \\
\hline & $(0.61)$ & (5.15) & $(5.56)$ \\
\hline \multirow[t]{2}{*}{ No Information } & - & -1.90 & 1.92 \\
\hline & & $(5.62)$ & (6.13) \\
\hline \multirow[t]{2}{*}{ Signals } & & - & $-0.80 * *$ \\
\hline & - & & $(0.33)$ \\
\hline \multirow[t]{2}{*}{ True Value } & & - & -0.00 \\
\hline & & & $(0.00)$ \\
\hline Observations & 250 & 300 & 300 \\
\hline \multicolumn{4}{|c|}{ Significance of Wald tests of coefficient equality } \\
\hline & $* * *$ \\
\hline = Distribution & $* * *$ & & \\
\hline$=$ High Cost & $* * *$ & & \\
\hline$=$ No Information & - & & \\
\hline Full Information & $* * *$ & $* *$ & $* *$ \\
\hline$=$ High Cost & $* * *$ & $* * *$ & $* * *$ \\
\hline$=$ No Information & - & & $* *$ \\
\hline \multicolumn{4}{|l|}{ Distribution } \\
\hline \multicolumn{4}{|l|}{$=$ High Cost } \\
\hline$=$ No Information & - & & \\
\hline \multicolumn{4}{|l|}{$\begin{array}{l}\text { High Cost } \\
=\text { No Information }\end{array}$} \\
\hline \multicolumn{4}{|c|}{$\begin{array}{l}*, * * \text {, and } * * * \text { denote significance at the } 10 \%, 5 \% \text {, and } 1 \% \text { level respectively. Standard errors are } \\
\text { clustered at the session level. Number of clues and number of transactions are market period level } \\
\text { observations. Results produced with panel regressions with standard errors (reported in } \\
\text { parentheses) clustered at the session level. As no signals are available for purchase in the No } \\
\text { Information treatment, the data from these sessions are excluded from specification [1]. The } \\
\text { number of observations is equal to the number of sessions ( } 25 \text { or } 30) \text { multiplied by the number of } \\
\text { market periods (10). }\end{array}$} \\
\hline
\end{tabular}




\subsection{Conjecture II. Informational Efficiency}

We now turn to the conjecture regarding informational efficiency. We want to assess how well market prices reflect aggregate information and reveal the underlying value of the asset when information is costly. Figure 1 plots the average price per period averaged over sessions for each treatment. The square markers in the figure indicate the underlying true value of the asset each period. Appendix B contains plots of all transactions for each session by treatment. Casual inspection of Figure 1 suggests that prices do not closely match asset value. The observed path prices are fairly flat and even the Full Information and Precise treatments which have the most information still do not come close to approaching prices of 50 or 490 when those are the true values of the asset. 
Fig. 1 Average Market Prices by Period for Each Treatment

Panel A. Treatments expected to exhibit lower informational efficiency than Baseline

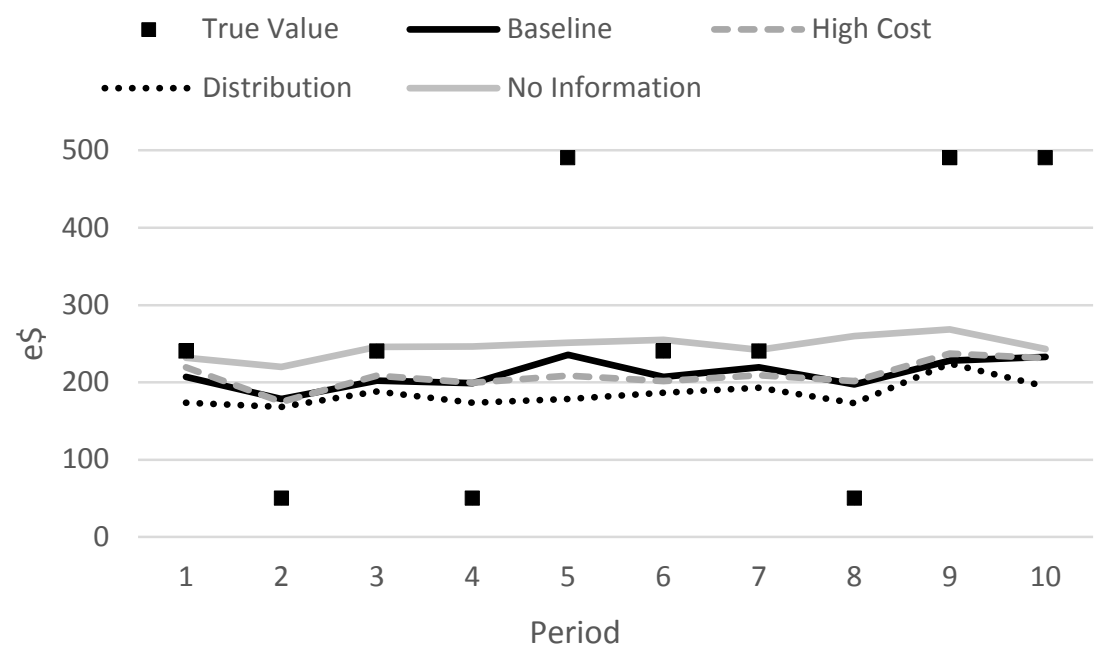

Panel B. Treatments expected to exhibit higher informational efficiency than Baseline

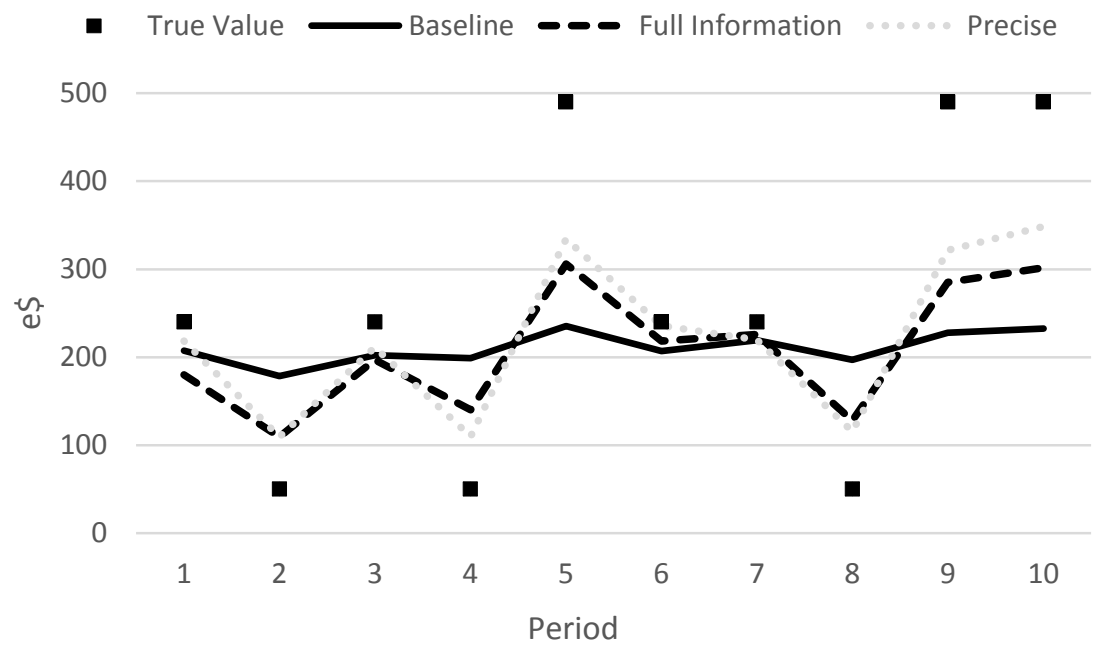

To quantify the degree to which prices reflect the underlying value, we present Table 4 . The dependent variable in this regression is the absolute price error, calculated as the absolute difference between the observed "price" in a period and the true value of the asset (see Table 2 for descriptive statistics on the absolute price error across treatments). The analysis is conducted separately for both the average price in a period and the closing price which we define as the average of the last three transactions in the period. Three specifications are reported for each measure of observed price and standard errors are clustered at the session 
level. The first specification (Columns [1] and [4]) includes binary dummy variables for each treatment, a variable indicating the market period, and an intercept. The second specification (Columns [2] and [5]) augments the first with variables corresponding to the number of signals acquired in the period, the number of transactions in the period, and the asset value $(50,240$, or 490). The regression results (and associated Wald tests at the bottom of Table 4) indicate that in terms of average price the Full Information and Precise treatments yields smaller absolute errors than the other treatments, but that the other treatments including No Information yield similar results. When considering closing prices the results differ as there is evidence that the No Information treatment has a greater absolute price error, at least in comparison to the Baseline, which would be expected as information is revealed through the course of trading. In each specification, period is positive and significant, but this may be due to the fact that the last three periods had extreme true value realizations (e\$50 or e\$490) which are cases in which prices are less in line with true value than when the value of the asset is e\$240 (see Figure 1). Our results support the relative ordering of treatments in terms of informational efficiency stated in Conjecture II. However, the difference in informational efficiency fails to reach statistical significance when comparing Baseline and the treatments that were predicted to exhibit less informational efficiency, High Cost and Distribution. The coefficient on Signals in specification two (Columns [2] and [5]) is negative but not significant. This seems to suggest that an increase in information does not reduce absolute price error; however, the amount of information is correlated with the treatments. Specification three (Columns [3] and [6]) considers the direct effect, absent the possible collinearity issues of specification [2], of the number of signals on absolute price error. The results clearly indicate that absolute price error is diminishing in total information thus confirming our Conjecture II that treatments characterized by more information acquisition will lead to greater informational efficiency. 
Table 4 Analysis of Absolute Price Error

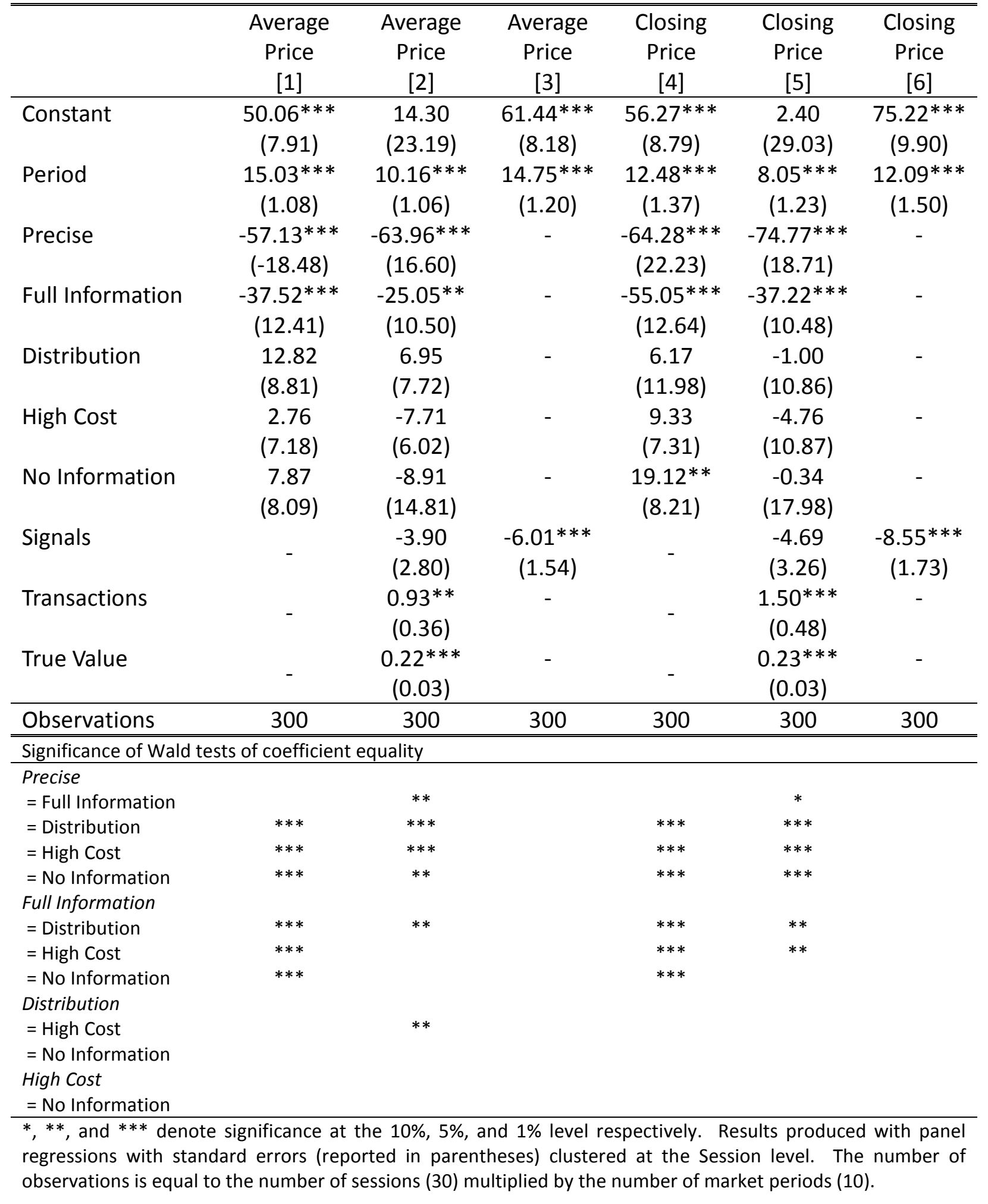

Overall, our findings indicate that market prices do not perfectly reflect the underlying value of the asset in line with the recent works of Corgnet et al. (2015) and Page and Siemroth (2017). 
We study further the extent to which our markets aggregate information by following the procedure of Plott and Sunder (1988) which assesses how close individual transaction prices are to the true value of the asset versus the predictions of the prior information (i.e. Walrasian) model (see, for example, Lintner, 1969) over an entire session. ${ }^{14}$ Under full revelation, market prices reflect all of the available information. Note that full revelation cannot occur in a rational expectations equilibrium without the presence of noise traders (see Grossman and Stiglitz, 1976). However, full revelation predictions constitute a useful benchmark to assess the extent to which prices aggregate private information. In any market with at least two clues full revelation implies that prices should equal the true value of the asset. In a market with no acquired clues the predicted price is 260 , which is the average of the three possible asset values. In a market with only one clue, the predicted price is the average value of the two noneliminated possible values. Let $T V$ denote the true value of the asset. For the prior information model, each trader updates her belief of the asset value based on any clues that are purchased, but does not update her beliefs based on market observables. Under this model, any trader would sell any held asset at a price above her private belief of the value. Similarly, any trader would buy as many assets as possible at any price below her private belief. Given each trader's prior information, one can calculate the excess demand at any price. The prior information model assumes excess demand will equal zero, but given the discrete nature of the market it is possible for a range of prices to generate zero excess demand. Let $\underline{P}_{\mathrm{PI}}$ and $\bar{P}_{\mathrm{PI}}$ denote the minimum and maximum price consistent with the prior information model, respectively. We define the mean absolute deviation from true value $\left(M A D_{T V}\right)$ and the mean absolute deviation from prior information $\left(M A D_{P I}\right)$ as follows where $I$ is the set of transactions. ${ }^{15}$

$$
\begin{gathered}
M A D_{T V}=\sum_{i \in I}\left|P_{i}-T V\right| \\
M A D_{P I}=\sum_{i \in I} \max \left(P_{i}-\bar{P}_{P I}, P_{P I}-P_{i}, 0\right)
\end{gathered}
$$

For each treatment, other than No Information where the two variables coincide, we conduct a sign test on the value $M A D_{T V}-M A D_{P I}$, where each term is calculated at the session level. The results indicate that observed prices are more consistent with the prior information model than with the true value for Baseline, High Cost, and Distribution. For the Full Information and

\footnotetext{
${ }^{14}$ Plott and Sunder (1988) also consider the Maximin model but we do not evaluate it here because Corgnet et al. (2015) have shown that the prior information model was the most accurate model to predict asset prices in these markets.

${ }^{15} M A D_{T V}$ is not equivalent to the absolute price error variable noted in Tables 2 and 4 . While the absolute price error measures the difference between the average price per period and the true asset value, the $M A D_{T V}$ sums the magnitudes of the deviations between price and true value for each transaction in a session across all periods.
} 
Precise treatments, true value and prior information predictions have similar explanatory power. ${ }^{16}$

The lack of full information aggregation implies that acquiring costly information may be profitable to a trader. This is the case because signals are only valuable in informationally inefficient markets. But the fact that market prices do not equal the true value of the asset does not mean prices do not provide any information about the underlying value of the asset. For each session, we calculate the correlation between the average price in a period and the true value of the asset that period. The average correlation between price and value was 0.90 for Full Information and 0.91 for Precise. Based on Mann Whitney tests of session level correlation, the correlation is greater in Full Information and Precise than in any other treatment (all p-values < 0.05). ${ }^{17}$ For Baseline and High Cost the average correlations are 0.69 and 0.59 respectively. These two treatments are not different from each other ( $p$-value $>0.05$ ), but both have higher correlation than Distribution and No Information (all p-values $<0.05$ ). The average correlations in Distribution and No Information are 0.27 and 0.13 , respectively, and these two treatments do not differ from each other ( $p$-value $>0.05$ ). Thus, with the exception of the Distribution treatment, the average market price can convey information when traders can acquire costly information. This is an important but subtle point. Viewed in isolation the average price in a market may not be informative. However, once the central tendencies of a market are identified then minor changes in price patterns can reveal substantial insights into the traders' private signals.

\subsection{Conjecture III. Individual Behavior}

In contrast to Page and Siemroth (2017) who focus on risk aversion and market experience, we investigate the cognitive aspects of the decision to purchase information. In specifications [1] and [2] of Table 5, we report the results of panel regressions with standard errors clustered at the session level with the dependent variable (Information Acquisition dummy) set to one if the trader purchased any information and zero otherwise. ${ }^{18}$ Specifications [3] and [4] of Table 5 report results of similar analyses using panel probit regressions. The independent variables for cognitive reflection and theory of mind are standardized scores based on the number of correct answers on each test (Appendix C provides more information about subject performance on the CRT and ToM tests). In both specifications, males are significantly more likely to purchase information than females even when controlling for cognitive reflection and theory of mind.

\footnotetext{
${ }^{16}$ Formally we test the null hypothesis of no MAD difference between the prior information predictions and the true value against the alternative that the prior information predictions lead to a lower MAD. Using session level data, the p-value for the sign test is 0.0313 for Baseline, High Cost, and Distribution. For both Full Information and Precise the $p$-value is 0.500 .

${ }^{17}$ The correlation between average price and true value is not different between Full Information and Precise.

${ }^{18}$ We focus on this variable rather than on the number of clues purchased because at the level of the individual in a market clues purchased can take on limited values that differ by treatment. Refer to Appendix $D$ for results corresponding to the same specification as regression [4] in Table 5 but with number of clues as the dependent variable.
} 
On average, males acquired $28 \%$ more signals than females. This finding is consistent with the fact that risk-averse individuals are less likely to acquire costly information (see Cabrales, Gossner and Serrano, 2017; Page and Siemroth, 2017) because women typically exhibit higher degrees of risk aversion than men (e.g. Croson and Gneezy, 2009). In addition, a higher theory of mind score is marginally related to an increase in information acquisition.

Table 5 Influence of Trader Characteristics on Decision to Acquire Information

\begin{tabular}{|c|c|c|c|c|c|}
\hline & $\begin{array}{c}\text { Information } \\
\text { Acquisition } \\
\text { Dummy } \\
{[1]}\end{array}$ & $\begin{array}{c}\text { Information } \\
\text { Acquisition } \\
\text { Dummy } \\
{[2]}\end{array}$ & $\begin{array}{c}\text { Information } \\
\text { Acquisition } \\
\text { Dummy } \\
{[3]}\end{array}$ & $\begin{array}{c}\text { Information } \\
\text { Acquisition } \\
\text { Dummy } \\
{[4]}\end{array}$ & $\begin{array}{c}\text { Information } \\
\text { Share } \\
{[5]}\end{array}$ \\
\hline Constant & $\begin{array}{c}0.49 * * * \\
(0.05)\end{array}$ & $\begin{array}{c}0.59 * * * \\
(0.07)\end{array}$ & $\begin{array}{c}-0.00 \\
(0.24)\end{array}$ & $\begin{array}{c}0.49 * \\
(0.26)\end{array}$ & $\begin{array}{c}0.11^{* * *} \\
(0.01)\end{array}$ \\
\hline Male & $\begin{array}{c}0.12 * * \\
(0.06)\end{array}$ & $\begin{array}{c}0.13^{* *} \\
(0.06)\end{array}$ & $\begin{array}{c}0.54 * * \\
(0.26)\end{array}$ & $\begin{array}{c}0.54 * * \\
(0.26)\end{array}$ & $\begin{array}{c}0.04 * * \\
(0.02)\end{array}$ \\
\hline $\begin{array}{l}\text { Cognitive } \\
\text { Reflection }\end{array}$ & $\begin{array}{c}0.01 \\
(0.02)\end{array}$ & $\begin{array}{c}0.01 \\
(0.02)\end{array}$ & $\begin{array}{c}0.11 \\
(0.10)\end{array}$ & $\begin{array}{c}0.12 \\
(0.11)\end{array}$ & $\begin{array}{c}0.00 \\
(0.01)\end{array}$ \\
\hline Theory of Mind & $\begin{array}{l}0.04 * \\
(0.02)\end{array}$ & $\begin{array}{l}0.05^{*} \\
(0.02)\end{array}$ & $\begin{array}{l}0.20 * \\
(0.10)\end{array}$ & $\begin{array}{l}0.20 * \\
(0.11)\end{array}$ & $\begin{array}{c}0.02 * * \\
(0.01)\end{array}$ \\
\hline Period & $\begin{array}{l}-0.01^{*} \\
(0.00)\end{array}$ & $\begin{array}{l}-0.01 * \\
(0.00)\end{array}$ & $\begin{array}{l}-0.04 * \\
(0.02)\end{array}$ & $\begin{array}{l}-0.04 * \\
(0.02)\end{array}$ & $\begin{array}{c}0.00 \\
(0.00)\end{array}$ \\
\hline Precise & - & $\begin{array}{l}-0.04 \\
(0.08)\end{array}$ & - & $\begin{array}{c}-0.24 \\
(-0.35)\end{array}$ & $\begin{array}{c}0.00 \\
(0.00)\end{array}$ \\
\hline Full Information & - & $\begin{array}{l}-0.07 \\
(0.08)\end{array}$ & - & $\begin{array}{c}-0.36 \\
(0.36)\end{array}$ & $\begin{array}{l}(-0.00) \\
(0.00)\end{array}$ \\
\hline Distribution & - & $\begin{array}{c}-0.19 * * \\
(0.08)\end{array}$ & - & $\begin{array}{c}-0.90 * * * \\
(0.30)\end{array}$ & $\begin{array}{l}-0.00 \\
(0.01)\end{array}$ \\
\hline High Cost & - & $\begin{array}{c}-0.22 * * * \\
(0.07)\end{array}$ & - & $\begin{array}{c}-0.95 * * * \\
(0.25)\end{array}$ & $\begin{array}{l}-0.00 \\
(0.00)\end{array}$ \\
\hline Observations & 2,000 & 2,000 & 2,000 & 2,000 & $1,976^{19}$ \\
\hline \multicolumn{6}{|c|}{$\begin{array}{l}*, * * \text { and } * * * \text { denote significance at the } 10 \%, 5 \% \text {, and } 1 \% \text { level respectively. The regressions include a random } \\
\text { effect for each subject. Standard errors (reported in parentheses) are clustered at the session level. Data from the } \\
\text { No Information treatment is excluded as these traders did not have the option to acquire signals. Results for } \\
\text { specifications [1], [2], and [5] are produced with panel regressions. Specifications [3] and [4] report results for } \\
\text { panel probit regressions corresponding to the analyses conducted in Specifications [1] and [2], respectively. The } \\
\text { number of observations is equal to the number of subjects (200) multiplied by the number of market periods (10). } \\
\text { For specifications that include Information Share, the number of observations was reduced because this value is } \\
\text { undefined when individuals could purchase information but no one in the market did. }\end{array}$} \\
\hline
\end{tabular}

${ }^{19}$ In 24 markets (out of 2,000) in which traders could purchase information no traders buy any information so that Information Share could not be calculated. 
Finally, we test conjecture III by studying trader earnings as a function of their cognitive skills. Table 6 reports the results of panel regressions for trader earnings (excluding the cost of acquiring signals). The results reveal that information does help traders earn a profit in the market. In specification [2] of Table 6 the coefficient on Information Acquisition, is positive and highly significant. In specification [3] of Table 6 the coefficient on Information Share, the number of signals purchased by a trader divided by the total number of signals purchased in the market period, is also positive and highly significant. The positive relationship between Information Share and trader profit puts forth that traders who are able to buy information when others do not will be able to extract more value from their purchased clues. The capacity to anticipate others' clue purchasing behavior requires understanding other people intentions. Because theory of mind skills capture one's capacity to read other people intentions, it could explain why traders who scored higher on the theory of mind test were more likely to buy clues when others did not thus holding a higher Information Share than other traders (see column [5] of Table 5). Interestingly, cognitive skills do not predict a trader's Information Share thus putting forth that such behavior is specific to high theory-of-mind traders. This result nicely complements the work of Bruguier et al. (2010) who show that theory of mind skills could help a trader predict the presence of insiders in the market. Our finding goes one step further by showing that theory of mind skills can also help traders predict others' information purchases decisions thus being able to buy when others do not. 
Table 6 Influence of Trader Characteristics on Trading Profit

\begin{tabular}{|c|c|c|c|c|c|}
\hline & $\begin{array}{c}\text { Trading } \\
\text { Profit } \\
\text { [1] }\end{array}$ & $\begin{array}{c}\text { Trading } \\
\text { Profit } \\
\text { [2] }\end{array}$ & $\begin{array}{c}\text { Trading } \\
\text { Profit } \\
\text { [3] }\end{array}$ & $\begin{array}{c}\text { Trading } \\
\text { Profit } \\
{[4]} \\
\end{array}$ & $\begin{array}{c}\text { Trading } \\
\text { Profit } \\
\text { [5] }\end{array}$ \\
\hline Constant & $\begin{array}{c}-54.90^{* *} \\
(26.85)\end{array}$ & $\begin{array}{c}-128.11^{* * *} \\
(32.58)\end{array}$ & $\begin{array}{c}-126.67^{* * *} \\
(35.88)\end{array}$ & $\begin{array}{c}-159.54^{* * *} \\
(30.81)\end{array}$ & $\begin{array}{c}-127.76^{* * *} \\
(28.00)\end{array}$ \\
\hline Male & $\begin{array}{c}135.83^{* *} \\
(61.96)\end{array}$ & $\begin{array}{c}112.17^{* *} \\
(55.13)\end{array}$ & $\begin{array}{c}131.36^{* *} \\
(65.99)\end{array}$ & $\begin{array}{c}112.28^{* *} \\
(55.05)\end{array}$ & $\begin{array}{c}131.09 * * \\
(66.18)\end{array}$ \\
\hline Cognitive Reflection & $\begin{array}{c}79.96 * * \\
(34.85)\end{array}$ & $\begin{array}{c}83.51 * * * \\
(32.19)\end{array}$ & $\begin{array}{c}87.39 * * \\
(37.82)\end{array}$ & $\begin{array}{c}82.32^{* *} \\
(33.40)\end{array}$ & $\begin{array}{c}89.04 * * \\
(38.79)\end{array}$ \\
\hline Theory of Mind & $\begin{array}{c}82.67^{* *} \\
(34.36)\end{array}$ & $\begin{array}{c}78.07^{* *} \\
(32.16)\end{array}$ & $\begin{array}{c}85.74 * * \\
(34.47)\end{array}$ & $\begin{array}{l}76.32 * * \\
(32.18)\end{array}$ & $\begin{array}{c}86.01 * * \\
(34.53)\end{array}$ \\
\hline Period & $\begin{array}{c}0.00 \\
(0.00)\end{array}$ & $\begin{array}{l}1.26^{*} \\
(0.73)\end{array}$ & $\begin{array}{l}-0.00 \\
(0.00)\end{array}$ & $\begin{array}{l}1.30^{*} \\
(0.75)\end{array}$ & $\begin{array}{c}0.00 \\
(0.01)\end{array}$ \\
\hline $\begin{array}{l}\text { Information } \\
\text { Acquisition }\end{array}$ & 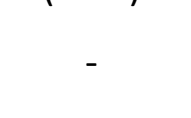 & $\begin{array}{c}185.20^{* * *} \\
(31.75)\end{array}$ & 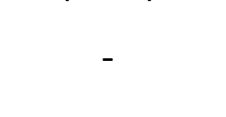 & $\begin{array}{c}191.40 * * * \\
(32.38)\end{array}$ & $x^{2}$ \\
\hline Information Share & - & - & $\begin{array}{c}663.77 * * * \\
(134.52)\end{array}$ & - & $\begin{array}{c}660.88^{* * *} \\
(134.23)\end{array}$ \\
\hline Precise & - & - & - & $\begin{array}{c}17.97 \\
(26.74)\end{array}$ & $\begin{array}{c}10.58 \\
(28.26)\end{array}$ \\
\hline Full Information & - & - & - & $\begin{array}{c}31.88 \\
(22.62)\end{array}$ & $\begin{array}{c}18.74 \\
(14.24)\end{array}$ \\
\hline Distribution & - & - & - & $\begin{array}{c}13.97 \\
(44.03)\end{array}$ & $\begin{array}{l}-23.05 \\
(36.06)\end{array}$ \\
\hline High Cost & - & - & - & $\begin{array}{l}44.38^{*} \\
(25.27)\end{array}$ & $\begin{array}{c}1.93 \\
(24.62)\end{array}$ \\
\hline No Information & - & - & - & $\begin{array}{l}63.46^{* *} \\
(31.23) \\
\end{array}$ & - \\
\hline Observations & 2,400 & 2,400 & 1,976 & 2,400 & 1,976 \\
\hline \multicolumn{6}{|c|}{$\begin{array}{l}*, * * \text { and } * * * \text { denote significance at the } 10 \%, 5 \% \text {, and } 1 \% \text { level respectively. Results produced with panel } \\
\text { regressions with standard errors (reported in parentheses) clustered at the session level. The regressions include a } \\
\text { random effect for each subject. As no signals are available for purchase in the No Information treatment, the } \\
\text { variable Information Share is undefined for this treatment and therefore data from these sessions are excluded } \\
\text { from specifications [3] and [5]. The number of observations is equal to the number of subjects ( } 240 \text { or } 200 \text { ) } \\
\text { multiplied by the number of market periods (10). For specifications that include Information Share, the number of } \\
\text { observations was reduced because this value is undefined when individuals could purchase information but no one } \\
\text { in the market did. }\end{array}$} \\
\hline
\end{tabular}

Conducting similar analyses by treatment yields the same finding, having information leads to greater trading profit (see specifications [4] and [5] of Table 6). The results in Table 6 also reveal that trading profits are higher for men, those with a high cognitive reflection score, and those with a high theory of mind score. These results are in line with Conjecture III thus confirming the results of Corgnet et al. (2017) in a context in which traders decide upon 
information acquisition and the amount of information in the market is thus endogenously determined by traders. ${ }^{20}$

While the results in Table 6 demonstrate the benefits of having information, they ignore the actual cost of that information. As it turns out, the benefit of information is less than its cost in each of the treatments considered. On average, traders only recoup $43.9 \%$ of their information cost. This is evidence of over-acquisition of information corroborating the results of Huber et al. (2011) and Page and Siemroth (2017). Over-acquisition is also demonstrated by the fact that traders consistently bought information in the High Cost treatment, when the cost of a signal was higher than its maximum possible value (see Table 2 for descriptive statistics). Overall, high cognitive reflection scores and high theory of mind scores are associated with greater total profit (including the cost of acquiring signals). Interestingly, the greater total profit of males is offset by their greater propensity to acquire information. The result is that on net there is no difference in total profit between males and females. These conclusions are supported by the estimations in Table 7.

\footnotetext{
${ }^{20}$ Following Corgnet et al. (2017), we also expect fluid intelligence to relate positively to trader earnings. However, we could not collect such measure (e.g. Raven test) given time constraints. Instead, we asked subjects to selfreport their SAT scores which can be seen as an alternative measure of fluid intelligence (Stanovich, 2009). We find that SAT scores, for those ( $85 \%$ of subjects) who reported it, relate positively although not significantly to trader profits. This is perhaps not surprising given the mild correlation between Raven scores and self-reported SAT scores $(\rho=0.11)$. See Corgnet et al. (2017) who reported this correlation for 732 subjects of the lab database at the same institution where we conducted our experimental sessions.
} 
Table 7 Influence of Trader Characteristics on Total Profit

\begin{tabular}{|c|c|c|c|c|c|c|}
\hline & $\begin{array}{c}\text { Total } \\
\text { Profit } \\
{[1]}\end{array}$ & $\begin{array}{c}\text { Total } \\
\text { Profit } \\
{[2]}\end{array}$ & $\begin{array}{c}\text { Total } \\
\text { Profit } \\
{[3]}\end{array}$ & $\begin{array}{c}\text { Total } \\
\text { Profit } \\
{[4]}\end{array}$ & $\begin{array}{c}\text { Total } \\
\text { Profit } \\
{[5]}\end{array}$ & $\begin{array}{c}\text { Total } \\
\text { Profit } \\
{[6]}\end{array}$ \\
\hline Constant & $\begin{array}{c}-194.40 * * * \\
(28.14)\end{array}$ & $\begin{array}{c}-117.14^{* * *} \\
(35.07)\end{array}$ & $\begin{array}{c}-187.74 * * * \\
(36.60)\end{array}$ & $\begin{array}{c}-215.48 * * * \\
(24.23)\end{array}$ & $\begin{array}{c}-100.64^{* * *} \\
(32.00)\end{array}$ & $\begin{array}{c}-181.66^{* * *} \\
(30.64)\end{array}$ \\
\hline Male & $\begin{array}{c}75.22 \\
(54.38)\end{array}$ & $\begin{array}{l}100.19^{*} \\
(55.67)\end{array}$ & $\begin{array}{l}111.38^{*} \\
(62.39)\end{array}$ & $\begin{array}{c}82.28 \\
(52.04)\end{array}$ & $\begin{array}{l}103.46^{*} \\
(54.76)\end{array}$ & $\begin{array}{l}113.04^{*} \\
(61.68)\end{array}$ \\
\hline $\begin{array}{l}\text { Cognitive } \\
\text { Reflection }\end{array}$ & $\begin{array}{c}89.53^{* * *} \\
(29.78)\end{array}$ & $\begin{array}{c}85.79 * * * \\
(32.61)\end{array}$ & $\begin{array}{c}88.97 * * \\
(38.94)\end{array}$ & $\begin{array}{l}79.88 * * \\
(31.28)\end{array}$ & $\begin{array}{l}81.81^{* *} \\
(33.90)\end{array}$ & $\begin{array}{c}86.46 * * \\
(39.59)\end{array}$ \\
\hline $\begin{array}{l}\text { Theory of } \\
\text { Mind }\end{array}$ & $\begin{array}{l}72.12 * * \\
(30.39)\end{array}$ & $\begin{array}{c}76.97 * * \\
(30.95)\end{array}$ & $\begin{array}{c}83.17^{* *} \\
(32.87)\end{array}$ & $\begin{array}{c}67.77^{* *} \\
(31.22)\end{array}$ & $\begin{array}{c}76.13^{* *} \\
(31.62)\end{array}$ & $\begin{array}{l}83.11^{* *} \\
(33.49)\end{array}$ \\
\hline Period & $\begin{array}{c}1.75 \\
(1.44)\end{array}$ & $\begin{array}{c}0.42 \\
(0.85)\end{array}$ & $\begin{array}{c}2.11 \\
(1.74)\end{array}$ & $\begin{array}{c}1.75 \\
(1.44)\end{array}$ & $\begin{array}{c}0.43 \\
(0.86)\end{array}$ & $\begin{array}{c}2.10 \\
(1.75)\end{array}$ \\
\hline $\begin{array}{l}\text { Information } \\
\text { Acquisition }\end{array}$ & - & $\begin{array}{c}-195.44^{* * *} \\
(36.15)\end{array}$ & - & - & $\begin{array}{c}-193.67^{* * *} \\
(37.52)\end{array}$ & - \\
\hline $\begin{array}{l}\text { Information } \\
\text { Share }\end{array}$ & - & - & $\begin{array}{c}-371.23 * * * \\
(121.74)\end{array}$ & - & - & $\begin{array}{c}-372.53^{* * *} \\
(121.74)\end{array}$ \\
\hline Precise & - & - & - & $\begin{array}{c}22.40 \\
(29.39)\end{array}$ & $\begin{array}{c}14.29 \\
(24.24)\end{array}$ & $\begin{array}{c}23.03 \\
(32.24)\end{array}$ \\
\hline $\begin{array}{l}\text { Full } \\
\text { Information }\end{array}$ & - & - & - & $\begin{array}{l}-36.60 \\
(33.56)\end{array}$ & $\begin{array}{c}-51.13^{* *} \\
(21.97)\end{array}$ & $\begin{array}{l}-35.77 \\
(34.64)\end{array}$ \\
\hline Distribution & - & - & - & $\begin{array}{c}35.75 \\
(50.74)\end{array}$ & $\begin{array}{c}-1.06 \\
(37.26)\end{array}$ & $\begin{array}{c}30.24 \\
(55.46)\end{array}$ \\
\hline High Cost & - & - & - & $\begin{array}{l}-43.38 \\
(40.79)\end{array}$ & $\begin{array}{c}-86.65^{* * *} \\
(26.23)\end{array}$ & $\begin{array}{l}-51.27 \\
(39.75)\end{array}$ \\
\hline $\begin{array}{l}\text { No } \\
\text { Information }\end{array}$ & - & - & - & $\begin{array}{c}131.21^{* * *} \\
(37.84)\end{array}$ & $\begin{array}{c}12.85 \\
(27.99)\end{array}$ & - \\
\hline Observations & 2,400 & 2,400 & 1,976 & 2,400 & 2,400 & 1,976 \\
\hline \multicolumn{7}{|c|}{$\begin{array}{l}*, * * \text {, and } * * * \text { denote significance at the } 10 \%, 5 \% \text {, and } 1 \% \text { level respectively. Results produced with panel } \\
\text { regressions with standard errors (reported in parentheses) clustered at the session level. The regressions include a } \\
\text { random effect for each subject. As no signals are available for purchase in the No Information treatment, the } \\
\text { variable Information Share is undefined for this treatment and therefore data from these sessions are excluded } \\
\text { from specifications [3] and [6]. The number of observations is equal to the number of subjects ( } 240 \text { or 200) } \\
\text { multiplied by the number of market periods (10). For specifications that include Information Share, the number of } \\
\text { observations was reduced because this value is undefined when individuals could purchase information but no one } \\
\text { in the market did. }\end{array}$} \\
\hline
\end{tabular}

\section{Discussion}

Much has been made of the success of markets in aggregating information; however, the aggregation in these markets is only as good as the information held by the traders. If traders are willing to invest in costly information under the belief that it can be used profitably in the 
market, then there is likely to be considerable privately held information. However, with wellinformed traders previous studies have found prices reflect aggregate private information (Plott and Sunder, 1988). Informational efficiency in the market reduces the benefit from acquiring information. So no one should acquire costly signals and there will be no information for the market to aggregate (see Grossman and Stiglitz, 1976).

This paper uses controlled laboratory experiments to investigate the puzzle of information aggregation when information is costly. Data were collected for a total of 240 subjects from six different experimental treatments that varied the cost of information and the amount of information that traders could acquire. In none of the treatments studied did the prices reveal more information than what is predicted by the prior information model. In fact, the prior information model best predicted prices in all treatments except for the two in which traders could become perfectly informed of the asset's value. The low level of informational efficiency of markets implied that private signals had a positive value. However, when studying individual behavior, we observe that information acquisition was counterproductive as those who did acquire more signals increased trading profits while decreasing their total profits, similar to Huber et al. (2011) and Page and Siemroth (2017). This finding echoes previous research on the sunk cost fallacy as well as previous works on overbidding in the experimental literature on contests (Dechenaux et al. 2015).

At the individual level, those with higher cognitive reflection scores and those with higher theory of mind scores tended to earn greater trading profits and total profits than those with lower scores. This extends the previous findings of Corgnet et al. (2017) to the case in which information is acquired at a cost and the level of information in a market is endogenous. Interestingly, males earned higher trading profits than females but this did not translate to a difference in total profit as males also tended to purchase more information.

While more research is warranted, as a whole our results suggest that, when information is costly for traders to acquire, markets may not fully aggregate the available information. This partly explains why traders acquire information at a cost. On the top of that, traders, especially males, are willing to acquire costly information to increase their gross earnings, possibly due to greater competitiveness and a search for status (e.g. Von Rueden et al. 2011). 


\section{References}

Anderson, Lisa and Charles Holt (1997) "Information Cascades in the Laboratory," American Economic Review, 847-862.

Arrow, Kenneth, Robert Forsythe, Michael Gorham, Robert Hahn, Robin Hanson, John Ledyard, Saul Levmore, Robert Litan, Paul Milgrom, Forrest Nelson, George Neumann, Marco Ottaviani, Thomas Schelling, Robert Shiller, Vernon Smith, Erik Snowberg, Cass Sunstein, Paul Tetlock, Philip Tetlock, Hal Varian, Justin Wolfers, and Eric Zitzewitz (2008) "The Promise of Prediction Markets," Science, 320.

Asparouhova, Elena, Peter Bossaerts and Wenhao Yang (2017) "Costly Information Acquisition in Decentralized Markets: An Experiment," Working Paper.

Baron-Cohen, Simon, Therese Jolliffe, Catherine Mortimore, and Mary Robertson (1997) "Another Advanced test of Theory of Mind: Evidence From Very High Functioning Adults With Autism or Asperger Syndrome," Journal of Child Psychology and Psychiatry 38, 813-822.

Berg, Joyce and Thomas Rietz (2003) "Prediction Markets as Decision Support Systems," Information Systems Frontiers, 5.

Biais, Bruno, Denis Hilton, Karine Mazurier, and Sébastien Pouget (2005) "Judgmental Overconfidence, Self-Monitoring and Trading Performance in an Experimental Financial Market," The Review of Economic Studies 72(2), 287-312.

Bossaerts, Peter, Cary Frydman and John Ledyard (2014) "The Speed of Information Revelation and Eventual Price Quality in Markets with Insiders: Comparing Two Theories," Review of Finance 18, 1-22.

Brüggelambert, Gregor (2004) "Information and Efficiency in Political Stock Markets: Using Computerized Markets to Predict Election Results," Applied Economics, 36(7).

Bruguier, Antoine, Steven Quartz, and Peter Bossaerts (2010) "Exploring the Nature of 'Trader Intuition'," Journal of Finance 65, 1703-1723.

Cabrales, Antonio, Olivier Gossner, and Roberto Serrano (2017) "A Normalized Value for Information Purchases," Journal of Economic Theory 170, 266-288.

Chen, Kay-Yut and Charlie Plott (2002) "Information Aggregation Mechanisms, Concept, Design and Field Implementation," Social Science Working Paper no. 1131, California Institute of Technology.

Chen, Yiling, Tracy Mullen and Chao-Hsien Chu (2006) "An In-Depth Analysis of Information Markets with Aggregate Uncertainty," Electronic Commerce Research 6, 201-222.

Choo, Lawrence, Todd Kaplan, and Ro'i Zultan (2017) "Information Aggregation in ArrowDebreu markets: An Experiment" Experimental Economics forthcoming. 
Corgnet, Brice, Mark DeSantis, and David Porter (2015) "Revisiting Information Aggregation in Asset Markets: Reflective Learning \& Market Efficiency." ESI Working Paper 15-15.

Corgnet, Brice, Mark DeSantis, and David Porter (2017) "What Makes a Good Trader? On the Role of Intuition and Reflection on Trader Performance," Journal of Finance (forthcoming).

Corgnet, Brice, Roberto Hernan-Gonzalez, Praveen Kujal and David Porter (2014) "The Effect of Earned Versus House Money on Price Bubble Formation in Experimental Asset Markets," Review of Finance 19, 1455-1488.

Cowgill, Bo, Justin Wolfers, and Eric Zitzewitz (2009) "Using Prediction Markets to Track Information Flows: Evidence from Google," in Auctions, Market Mechanisms and Their Applications Volume 14, eds. Sanmay Das, Michael Ostrovsky, David Pennock, and Boleslaw Szymanksi, Springer: Berlin.

Camerer, Colin, Anna Dreber, Eskil Forsell, Teck-Hua Ho, Jürgen Huber, Magnus Johannesson, Michael Kirchler, Johan Almenberg, Adam Altmejd, Taizan Chan, Emma Heikensten, Felix Holzmeister, Taisuke Imai, Siri Isaksson, Gideon Nave, Thomas Pfeiffer, Michael Razen, Hang $\mathrm{Wu}$ (2016) "Evaluating replicability of laboratory experiments in economics," Science 351 (6280), 1433-1436.

Croson, Rachel and Uri Gneezy (2009) "Gender Differences in Preferences," Journal of Economic Literature 47(2), 448-474.

Dechenaux, Emmanuel, Dan Kovenock, and Roman Sheremeta (2015) "A Survey of Experimental Research on Contests, All-pay Auctions and Tournaments," Experimental Economics 18, 609-669.

Deck, Cary and David Porter (2013) "Prediction Markets in the Laboratory," Journal of Economic Surveys 27(3), 589-603.

Duffie, Darrel, Semyon Malamud, and Gustavo Manso (2009) "Information Percolation with Equilibrium Search Dynamics," Econometrica 77, 1513-1574.

Forsythe, Robert and Russell Lundholm (1990) "Information Aggregation in an Experimental Market," Econometrica 58, 309-347.

Frederick, Shane (2005) "Cognitive Reflection and Decision Making," Journal of Economic Perspectives 19(4), 25-42.

Gillen, Benjamin, Charles Plott, and Matthew Shum (2017) "A Pari-Mutuel-Like Mechanism for Information Aggregation: A Field Test inside Intel," Journal of Political Economy 125(4), 10751099. 
Grossman, Sanford J. and Joseph E. Stiglitz (1980) "On the Impossibility of Informationally Efficient Markets," American Economic Review 70, 393-408.

Hanson, Robin and Ryan Oprea (2009) "A Manipulator Can Aid Prediction Market Accuracy," Economica 76, 304-314.

Hanson, Robin, Ryan Oprea, and David Porter (2006) "Information Aggregation and Manipulation in an Experimental Market," Journal of Economic Behavior and Organization 60, 449-459.

Hauser, Florian, Bob Kaempff and Jürgen Huber (2015) "Costly Information in Markets with Heterogeneous Agents: A Model with Genetic Programming," Computational Economics 46, 205-229.

Hayek, Friedrich (1945) "The Use of Knowledge in Society," American Economic Review 35(4), 519-530.

Hefti, Andreas, Steve Heinke, and Frederic Schneider (2016) “Mental Capabilities, Trading Styles and Asset Market Bubbles: Theory and Experiment," Research Gate Working Paper.

Huber, Jürgen (2007) '“J'-shaped Returns to Timing Advantage in Access to InformationExperimental Evidence and a Tentative Explanation," Journal of Economic Dynamics \& Control 31, 2536-2572.

Huber, Jürgen, Michael Kirchler and Martin Angerer (2011) "Experimental Asset Markets with Endogenous Choice of Costly Asymmetric Information," Experimental Economics 14(2), 223240.

Kirchler, Michael (2010) "Partial Knowledge is a Dangerous Thing - On the Value of Asymmetric Fundamental Information in Asset Markets," Journal of Economic Psychology 21, 643-658.

Jacobsen, Ben, Jan Potters, Arthur Schram, Frans Van Winden, and Jörgen Wit (2000) "(In)accuracy of a European Political Stock Market: The Influence of Common Value Structures," European Economic Review 44(2), 205-230.

Lintner, John (1969) "The Aggregation of Investor's Diverse Judgments and Preferences in Purely Competitive Security Markets," Journal of Financial and Quantitative Analysis 4(4), 347400.

Lundholm, Russell (1991) "What affects the efficiency of the market? some answers from the laboratory," The Accounting Review 66, 486-515.

Muth, John (1961) "Rational Expectations and the Theory of Price Movements," Econometrica, 29, 315-335.

Noussair, Charles, Steven Tucker and YiLong Xu (2014) "A Futures Market Reduces Bubbles But Allows Greater Profit for More Sophisticated Traders," SSRN Working Paper. 
Oechssler, Jorg, Andreas Roider and Patrick Schmitz (2009) "Cognitive Abilities and Behavioral Biases," Journal of Economic Behavior \& Organization 72(1), 147-152.

Page, Lionel and Christoph Siemroth (2017) "An Experimental Analysis of Information Acquisition in Prediction Markets," Games and Economic Behavior 101, 354-378.

Pennock, David, Steve Lawrence, C. Lee Giles, and Finn Årup Nielsen (2001) "The Real Power of Artificial Markets," Science 291(5506), 987-988.

Plott, Charles and Shyam Sunder (1982) "Efficiency of Experimental Security Markets with Insider Information: An Application of Rational-Expectations Models," Journal of Political Economy 90(4), 663-698.

Plott, Charles and Shyam Sunder (1988) "Rational Expectations and the Aggregation of Diverse Information in Laboratory Security Markets," Econometrica 56(5), 1085-1118.

Smith, Vernon, Suchanek, Gerry, and Arlington Williams (1988) "Bubbles, Crashes, and Endogenous Expectations in Experimental Spot Asset Markets," Econometrica 56(5), 1119-1151.

Stanovich, Keith (2009) "What intelligence tests miss: the psychology of rational thought," New Haven: Yale University Press.

Sunder, Shyam (1992) “Market for information: Experimental evidence," Econometrica 60(3), 667-695.

Toplak, Maggie, Richard West, and Keith Stanovich (2011) "The Cognitive Reflection Test as a Predictor of Performance on Heuristics and Biases Tasks," Memory \& Cognition 39, 1275-1289.

Toplak, Maggie, Richard West, and Keith Stanovich (2014) "Assessing Miserly Information Processing: An Expansion of the Cognitive Reflection Test," Thinking \& Reasoning 20(2), 147168.

Veiga, Helena and Marc Vorsatz (2010) "Information Aggregation in Experimental Asset Markets in The Presence of a Manipulator," Experimental Economics 13(4), 379-398.

Von Rueden, Christopher, Michael Gurven, and Hillard Kaplan (2011) "Why Do Men Seek Status? Fitness Payoffs to Dominance and Prestige," Proceedings of the Royal Society B: Biological Sciences 278(1715), 2223-2232. 


\section{Appendix A. Subject Instructions}

\section{Welcome!}

Please enter your name below to get started:

First and Last Name: $\quad$ E.g. John Smith

Submit

\section{Introduction}

This is an experiment in the economics of market decision making. You will be paid in cash at the end of the experiment based upon the decisions you make, so it is important that you understand the directions completely. If you have a question, please raise your hand and a monitor will approach you. Otherwise, you should not communicate in any way with anyone else.

In this experiment we are going to simulate a market in which you can buy and sell shares with other participants in the experiment. The currency is called Experimental Dollars (e-Dollars) and at the end of the experiment your e-Dollars will be converted into $\$ U S$ at the rate $\$ 1=1,000 \mathrm{e}$-Dollars. 


\section{Trading Market Periods}

The experiment is broken up into a sequence of 10 market periods. Each period you can trade shares that will pay their owner either $50 \mathrm{e}-\mathrm{Dollars}$, 240 e-Dollars or 490 e-Dollars.

In a given period, all shares will pay the same amount regardless of who owns the shares. This amount is randomly determined for each market period. This means that the amount shares pay in one market period does not provide any information about what amount shares will pay in another market period. It also means that the amount is equally likely to be 50,240 or 490 in a period.

You will start each period with a balance of 1,200 e-Dollars and 4 shares. Any time you buy shares the price you pay is deducted from your balance. Any time you sell shares, the price is added to your balance. At the end of the period, the payment from any shares you own will be added to your balance. Your earnings for the period are based on your final e-Dollar balance. e-Dollars and shares do not carry over from one market period to the next.

\section{Information}

Each period all shares are worth either $50 \mathrm{e}$-Dollars, $240 \mathrm{e}$-Dollars or $490 \mathrm{e}$-Dollars.

Before trading begins each market period, you will have the opportunity to receive information about the value of shares in the upcoming period. The information, called a clue, will tell you a value that the shares will not take.

If shares are actually worth $50 \mathrm{e}$-Dollars

- one possible clue is that e-Dollars are not worth 240 e-Dollars

- one possible clue is that e-Dollars are not worth $490 \mathrm{e}$-Dollars

Similarly if shares are actually worth 240 e-Dollars

- one possible clue is that e-Dollars are not worth 50 e-Dollars

- one possible clue is that e-Dollars are not worth $490 \mathrm{e}$-Dollars

And if shares are actually worth $490 \mathrm{e}$-Dollars

- one possible clue is that e-Dollars are not worth $50 \mathrm{e}$-Dollars

- one possible clue is that e-Dollars are not worth 240 e-Dollars 


\section{Acquiring Information}

A clue costs 300 e-Dollars.

Each period, you are given a budget of $600 \mathrm{e}$-Dollars for purchasing clues. Any of these e-Dollars that are not spent on clues are automatically added to your e-Dollar balance at the end of the market period; but they cannot be used for buying and selling shares.

No one is required to purchase a clue, and everyone has the option to purchase 1 clue.

If you purchase a clue, which possible clue you receive is determined randomly. The computer program will ensure that the number of traders receiving each possible clue is as equal as possible. That is, if shares are worth $50 \mathrm{e}$-Dollars and 6 people purchase one clue, then 3 people will receive the clue that shares are not worth $240 \mathrm{e}$-Dollars and 3 people will receive the clue that shares are not worth $490 \mathrm{e}$-Dollars.

\section{Trading Interface Instructions}

Now that you have an overview of the experiment, we will talk in more detail about how you buy and sell shares.

A table at the right hand side of your screen will show "Your Holdings". These consist of any e-Dollars remaining from your Clue Budget, your current e-Dollars (Cash) and the shares you own in the current period. This table also displays your Cumulative Profits, which represent your earnings from all prior periods (including any e-Dollars from your Clue Budget that you did not spend in prior periods).

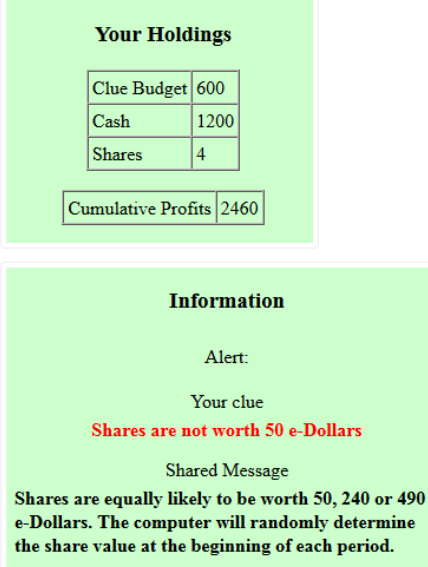




\section{Period Summary Information}

At the end of each period, the trading interface will display the value of a share for the period (50, 240 or 490), Share Value this Period, as well as your earnings for the period, Total e-Dollar Balance. This figure reflects the sum of your Clue Budget (any funds you did not spend to purchase a clue), your ending e-Dollar (Cash) balance for the period and the value of the shares you are holding at the end of the period.

While the Total e-Dollar Balance represents your earnings for the period, Cumulative Profits reflects your earnings for the current period as well as all earlier periods.

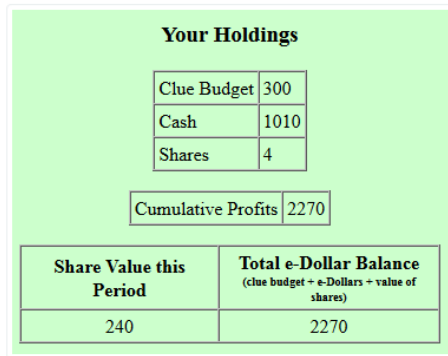

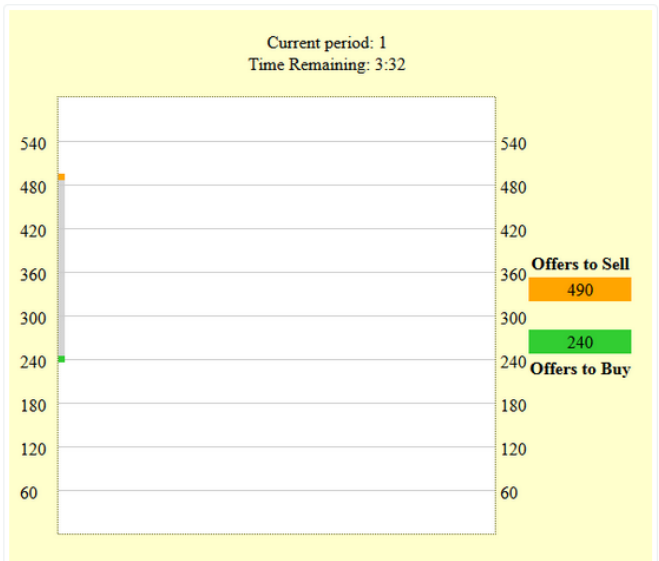

\section{Market Graph}

During every period, participants can buy or sell shares from one another by making offers to buy or to sell. The existing offers are shown on the Market Graph to the left. On top of the graph, the current period is shown. Below that, the Time Remaining for the trading period is shown. Each period lasts four minutes. The vertical axis lists the Price for the offers.

Every time someone makes an offer to buy a share, a GREEN dot will appear on the graph to the left. Every time someone makes an offer to sell, an ORANGE dot will appear on the graph to the left. Once a trade is actually made, the trade will be shown as a BLACK dot in the graph. Offers are also listed on the Offer Book to the right of the graph. 


\section{Making Offers}

To accept an existing offer from another participant, click the Buy or Sell button in the Immediate Offer section below. The Immediate Offer section shows you the best prices to buy, or sell, that are currently available in the market.

Suppose you want to place an offer to buy, it must be higher than the current best offer to buy, which is now 240 . Say you want to buy at 250. You will have to type in 250 and click the Buy button. Please do exactly that on your screen by typing 250 in the Submit New Offer (buy) box and clicking on the Buy button (below).

$\begin{array}{lll}\text { Submit New Offer } & \text { buy } \sqrt{ } & \text { sell } \sqrt{ } \\ \text { Immediate Offer } & \text { buy } \sqrt{490} & \text { sell } \sqrt{240}\end{array}$

PREVIOUSPAGE

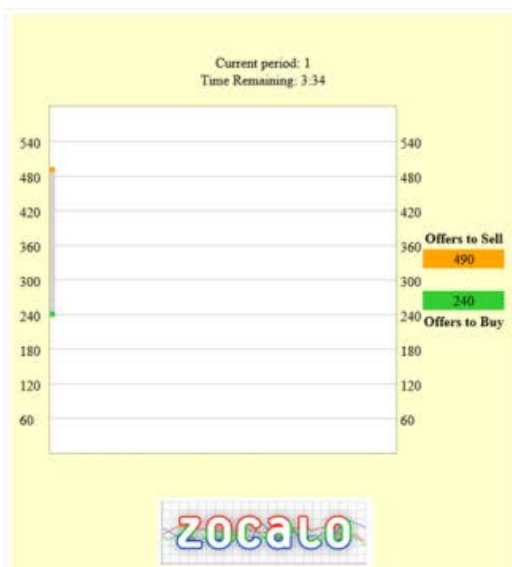

\section{Making Offers}

To accept an existing offer from another participant, click the Buy or Sell button in the Immediate Offer section below. The Immediate Offer section shows you the best prices to buy, or sell, that are currently available in the market.

Suppose you want to place an offer to buy, it must be higher than the current best offer to buy, which is now 240 . Say you want to buy at 250. You will have to type in 250 and click the Buy button. Please do exactly that on your screen by typing 250 in the Submit New Offer (buy) box and clicking on the Buy button (below).

$\begin{array}{lll}\text { Submit New Offer } & \text { buy } \sqrt{250} & \text { sell } \sqrt{ } \\ \text { Immediate Offer } & \text { buy } \sqrt{490} & \text { sell } \sqrt{240}\end{array}$

PREVIOUS PAGE
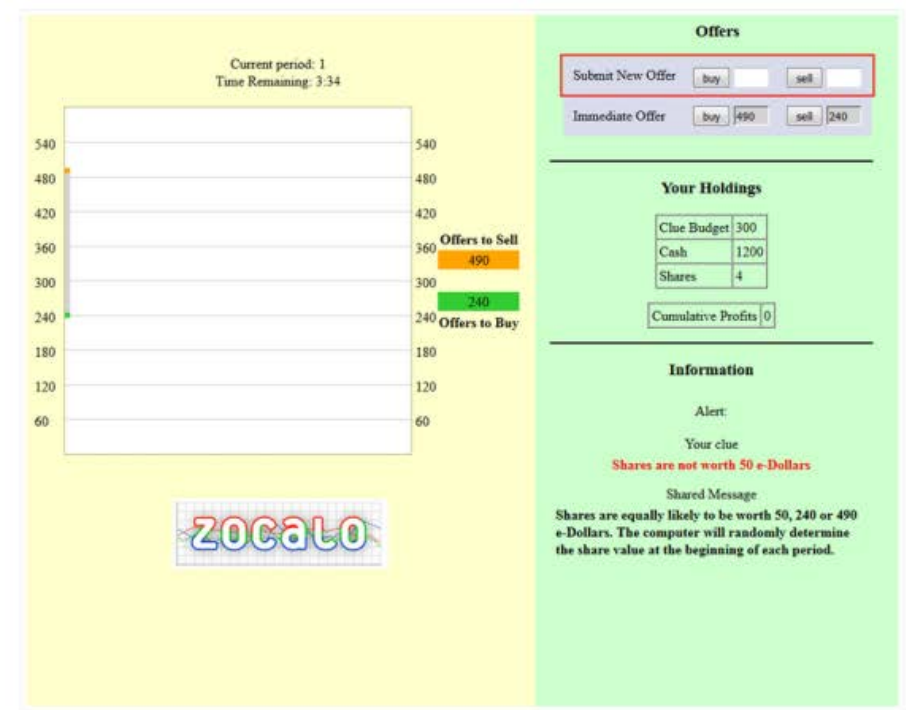


\section{Making Offers}

Notice your 250 Offer to Buy now appears in both the Market Graph and the Offer Book.

Next, suppose you want to place an offer to sell, it must be lower than the current best offer to sell, which is now 490 . Say you want to sell at 470 . You will have to type in 470 and click the Sell button. Please do exactly that on your screen by typing 470 in the Submit New Offer (sell) box and clicking on the Sell button (below).

$\begin{array}{lll}\text { Submit New Offer buy } & \text { sell } \sqrt{\square} \\ \text { Immediate Offer } & \text { buy } \sqrt{490} & \text { sell } \sqrt{250}\end{array}$

\section{PREVIOUSPAGE}

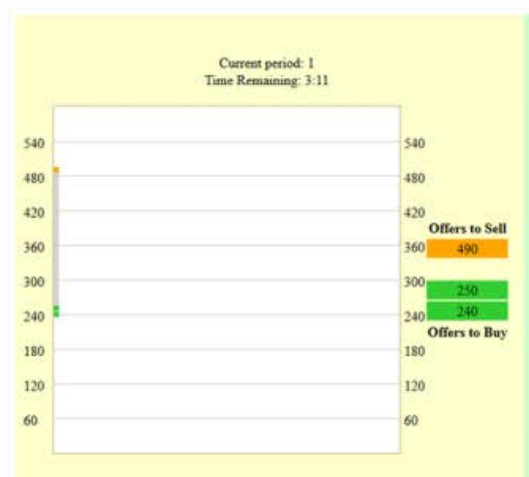

20GOLO:

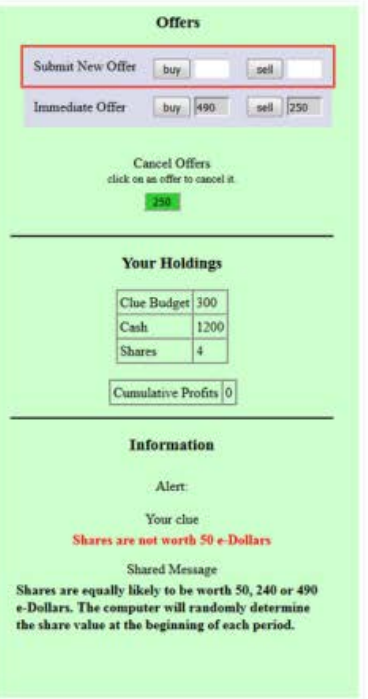

\section{Making Offers}

Notice your 250 Offer to Buy now appears in both the Market Graph and the Offer Book.

Next, suppose you want to place an offer to sell, it must be lower than the current best offer to sell, which is now 490 . Say you want to sell at 470 . You will have to type in 470 and click the Sell button. Please do exactly that on your screen by typing 470 in the Submit New Offer (sell) box and clicking on the Sell button (below).

$\begin{array}{lll}\text { Submit New Offer } & \text { buy } \sqrt{ } & \text { sell } \sqrt{470} \\ \text { Immediate Offer } & \text { buy } \sqrt{490} & \text { sell } \sqrt{250}\end{array}$

\section{PREVIOUS PAGE}

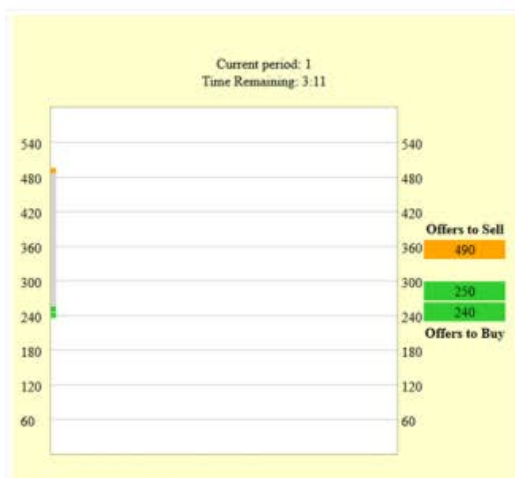

20GลLO 


\section{Making Offers}

Notice your 470 Offer to Sell now appears in both the Market Graph and the Offer Book.

Now that you have submitted new offers, click the NEXT PAGE button to practice accepting existing offers.

$\begin{array}{lll}\text { Submit New Offer } & \text { buy } \sqrt{ } & \text { sell } \sqrt{\square} \\ \text { Immediate Offer } & \text { buy } \sqrt{470} & \text { sell } \sqrt{250}\end{array}$

PREVIOUSPAGE

NEXT PAGE

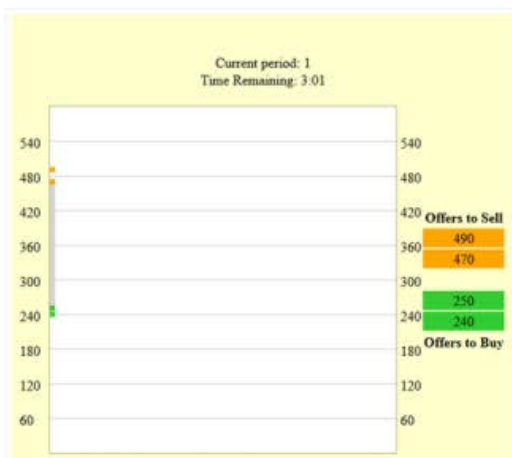

20GOLO:

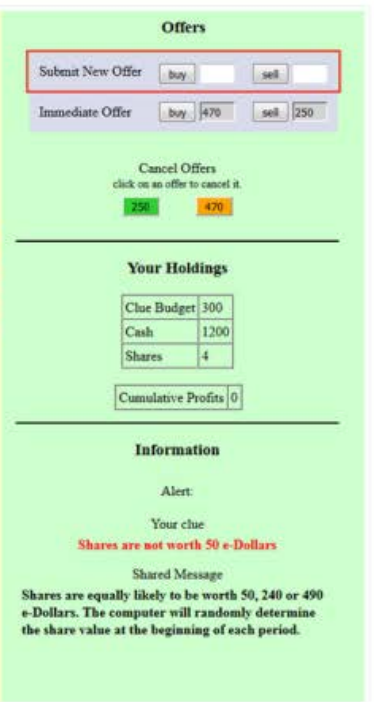

\section{Accepting Offers}

To accept an existing offer from another participant, click the Buy or Sell button in the Immediate Offer section below. This section shows you the best prices to buy, or sell, that are currently available on the market.

By clicking on the Sell button, you sell at the listed price. The current best offer to buy is 260 , if you click Sell, you sell a share at the price of 260 immediately. Your shares decrease by 1 , and your cash increases by 260 e-Dollars. This is reflected in the "Your

Holdings" box. Click the Sell button below to continue.

$\begin{array}{llll}\text { Submit New Offer } & \text { buy } \sqrt{ } & \text { sell } \sqrt{\square} \\ \text { Immediate Offer } & \text { buy } \sqrt{450} & \text { sell } \sqrt{260}\end{array}$

PREVIOUS PAGE

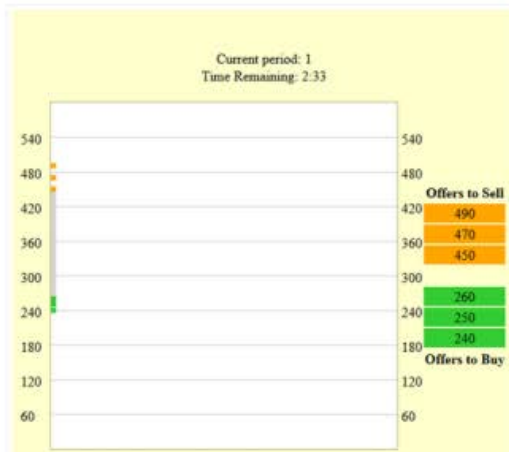

20Gล50:

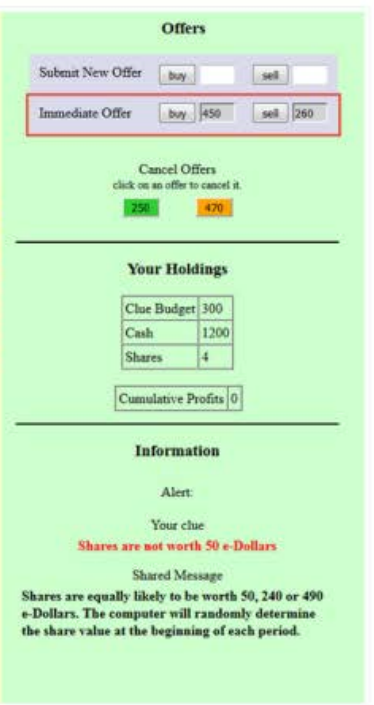




\section{Accepting Offers}

Notice your share sale of 260 is shown as a black dot in the Market Graph. Also, as noted in the "Your Holdings" box, your cash increased by $260 \mathrm{e}$-Dollars and your shares decreased by 1 .

Next, by clicking on the Buy button, you buy at the listed price. The current best offer to sell is 450. If you click Buy, you buy a share at the price of 450 immediately. Your shares will increase by 1 , and your e-Dollars will decrease by 450 . This is reflected in the "Your Holdings" box. Click the Buy button below to continue.

$\begin{array}{lll}\text { Submit New Offer } & \text { buy } \sqrt{\square} & \text { sell } \sqrt{ } \\ \text { Immediate Offer } & \text { buy } \sqrt{450} & \text { sell } \sqrt{250}\end{array}$

PREVIOUSPAGF

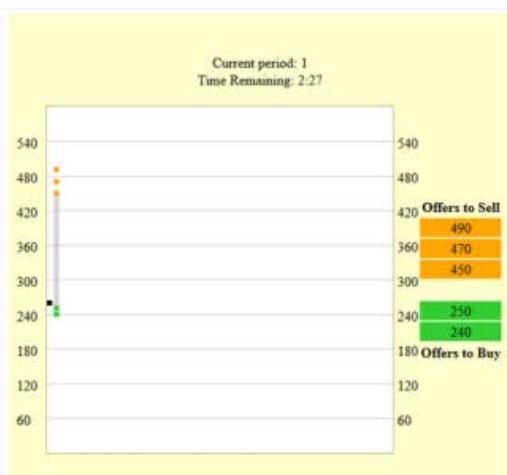

20லลㅇ:

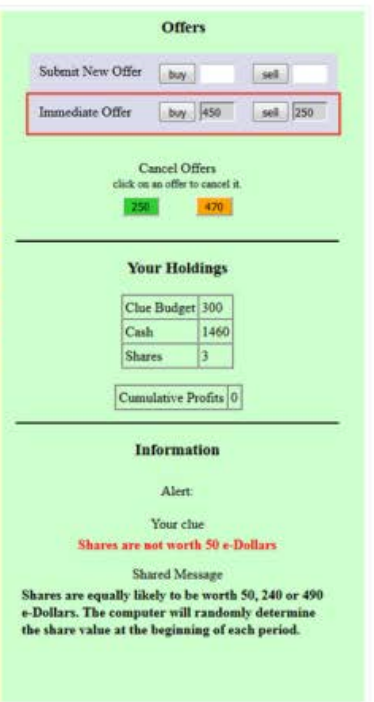

\section{Accepting Offers}

Notice your share purchase of 450 is shown as a black dot on the Market Graph. Also, as noted in the "Your Holdings" box, your cash decreased by $450 \mathrm{e}$-Dollars and your shares increased by 1 .

Now that you have accepted immediate offers, click the NEXT PAGE button to continue.

\begin{tabular}{ll|l|l|} 
Submit New Offer & buy $\sqrt{ }$ & sell $\sqrt{ }$ \\
Immediate Offer & buy $\sqrt{470}$ & sell $\sqrt{250}$ \\
\hline PREVIOUS PAGE & NEXT PAGE \\
\hline
\end{tabular}
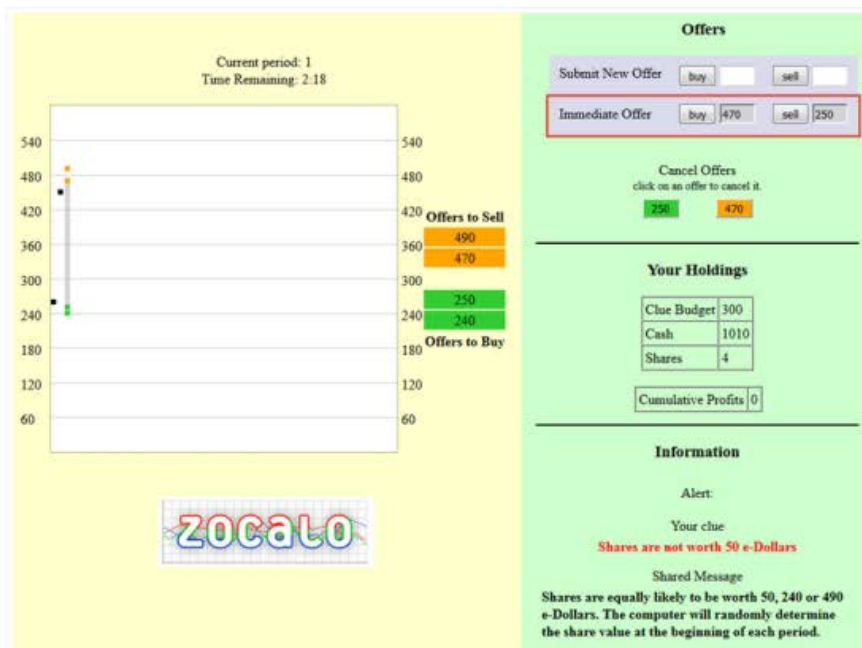


\section{Your Holdings}

As demonstrated on the previous pages, as you BUY shares, your holdings of shares will automatically increase and your cash will decrease. As you SELL shares, your cash will automatically increase and your holdings of shares will decrease. Your holdings of cash and shares as well as your Cumulative Profits (sum of the profits for each of the market periods) are displayed in the "Your Holdings" box.

\section{PREVIOUS PAGE}

NEXT PAGE

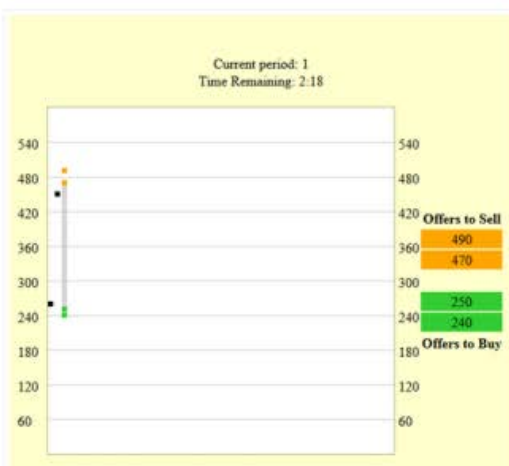

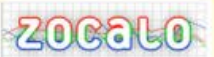

\section{Cancelling Offers}

When you enter new offers to buy or sell, those offers appear as Buttons below the offer box. The sum of your outstanding offers to buy cannot exceed your cash holding. Similarly, the total number of shares you are offering to sell cannot exceed the number of shares you currently own. Therefore, you may have to delete a current offer(s) in order to make new or updated offers. To do this, look for "Cancel Orders" and click on the corresponding button to remove your offer from the market.

For example, please remove your Offer to Buy of 250 from the market by clicking the green Offer to Buy button labeled " 250 ."

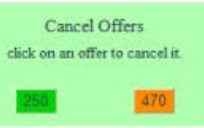

PREVIOUS PAGE
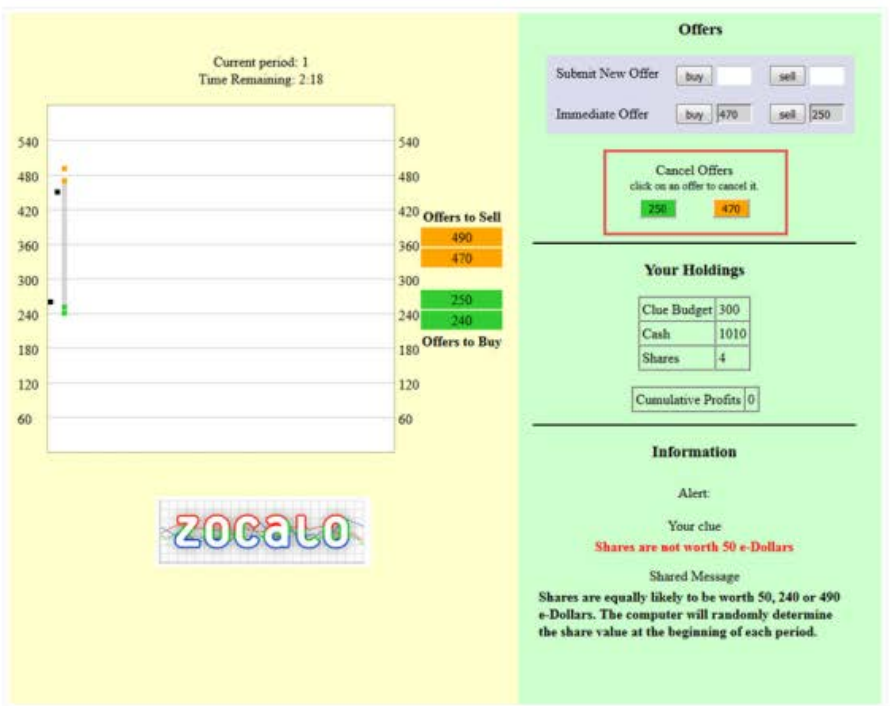


\section{Cancelling Offers}

Notice your Offer to Buy of 250 is no longer represented by a green dot in the Market

Graph or listed in the Offer Book.

Click NEXT PAGE to continue.

\begin{tabular}{|c|c|}
\hline $\begin{array}{c}\text { Cancel Offers } \\
\text { click on an offer to cancel it } \\
470\end{array}$ & \\
\hline PREVIOUS PAGE & NEXT PAGE \\
\hline
\end{tabular}
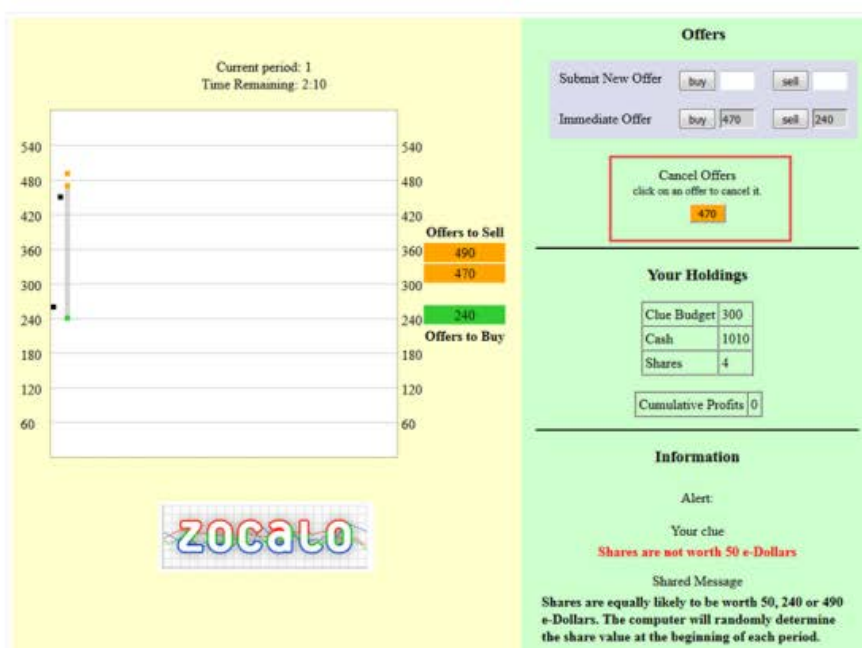

20BOR(B)

\section{Instructions Summary}

There will be a short quiz followed by a practice period to allow everyone to become familiar with entering offers and making trades, but before we do let's review the main points of the experiment.

1. Each market period you will start off with 1,200 e-Dollars and 4 shares.

2. Each market period the value of shares is equally likely to be 50,240 or 490 .

3. Clues reveal one of the values that shares will not take. A clue costs $300 \mathrm{e}$-Dollars.

4. You can buy and sell shares in the market. Submit New Offer is used to announce a price at which you want to buy or sell if someone else will

accept. Immediate Offers is used to instantly buy or sell a share at a price offered by another trader in the market.

5. Your earnings in a market period = your initial e-Dollars

+e-Dollars you receive from selling shares

- e-Dollars you spend buying shares

+ the value of any shares you hold at the end of the year

+ any e-Dollars you do not spend from your Clue Budget

Finally, your earnings for the experiment will be the sum of your earnings from each market period multiplied by the exchange rate. PREVIOUS PAGE 


\section{Review Quiz}

Please answer the following questions. After all participants have correctly answered them, as part of the instructions there will be a practice trading period to ensure you understand the software.

Question 1: At the end of each period, each share will be worth:

A. 0

ㄱ. B. 50.

C. Either 50,240 or 490 .

D. 490 .

Question 2: Which of the following statements is correct?

A. All share values $(50,240$ or 490$)$ are equally likely.

- B. 50 is more likely to occur than the other share values.

C. 490 will occur on average $50 \%$ of the time.

D. 240 is more likely to occur than the other share values.

Question 3: You can put a new offer to buy in the market by:

A. Clicking on the buy button when submitting a new offer to the market

B. Clicking on the sell button when submitting a new offer to the market

- C. Clicking on the sell button to accept an immediate offer available in the market

- D. Clicking on the buy button to accept an immediate offer available in the market

Question 4: You can accept an existing offer to sell in the market by:

A. Clicking on the buy button when submitting a new offer to the market

B. Clicking on the sell button when submitting a new offer to the market

- C. Clicking on the buy button to accept an immediate offer available in the market

D. Clicking on the sell button to accept an immediate offer available in the market

Question 5: The experiment will consist of a total of:

A. 8 market periods

B. 10 market periods

C. 12 market periods

D. 14 market periods

Question 6: If I receive the clue "not 490" at the beginning of a given period, this means:

A. Each share will be worth 490 at the end of the period.

B. Each share will NOT be worth 240 at the end of the period.

- C. Each share will NOT be worth 50 at the end of the period.

D. Each share will NOT be worth 490 at the end of the period. 


\section{Quiz Completed}

You have successfully completed the quiz.

The practice period will begin when everyone is ready.

Please wait quietly. 


\section{Appendix B. Transaction Data by Session}

We present plots of transaction prices (red circles) by period. The width of the period reflects its 240 second duration and trades are shown according to when they occurred. The true value is listed in parentheses at the bottom of each period and displayed as a solid horizontal line. The average price per period is listed at the top of each period. The price(s) predicted by the prior information model is (are) displayed as a dashed horizontal line(s). 


\section{Baseline}
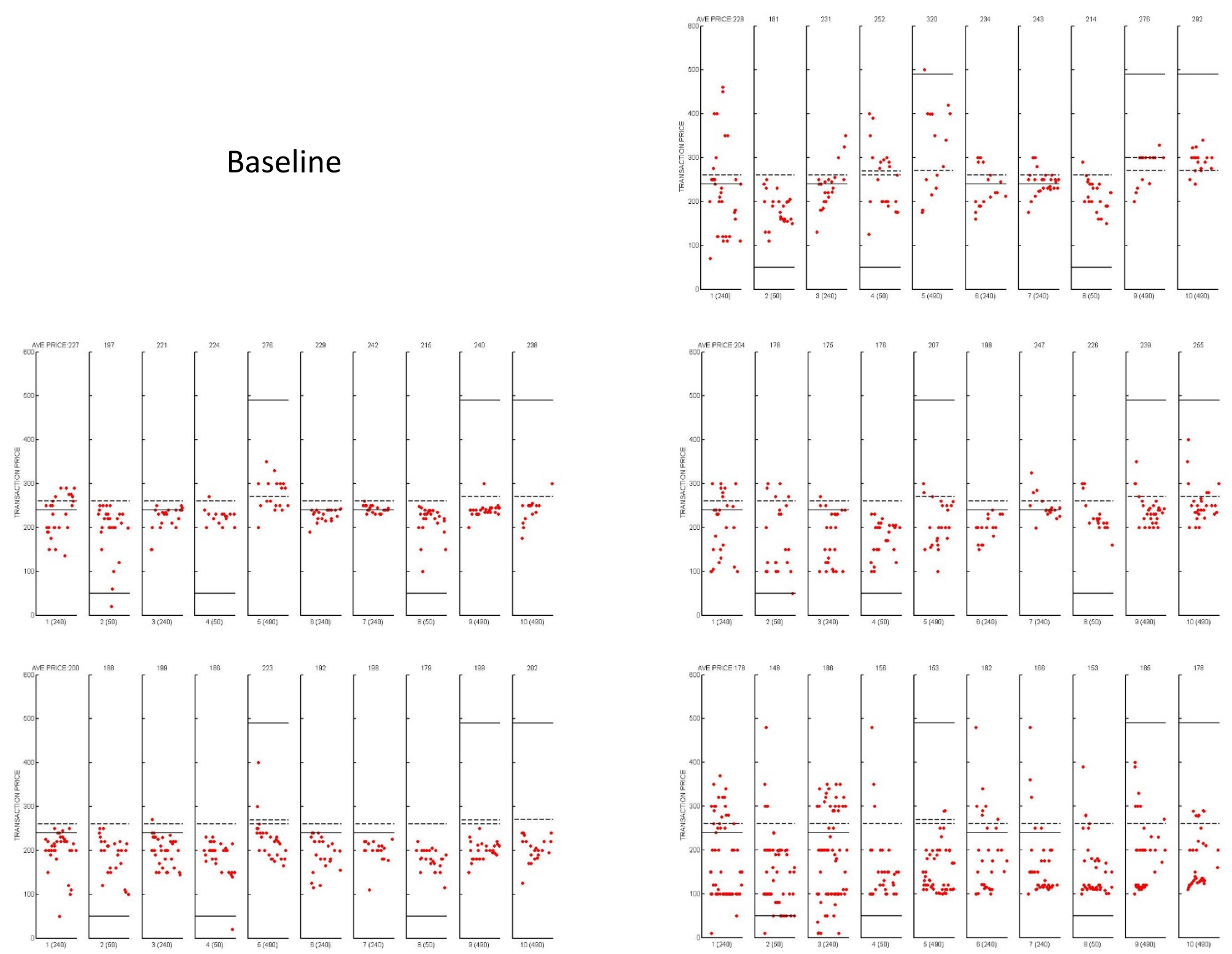


\section{Full Information}
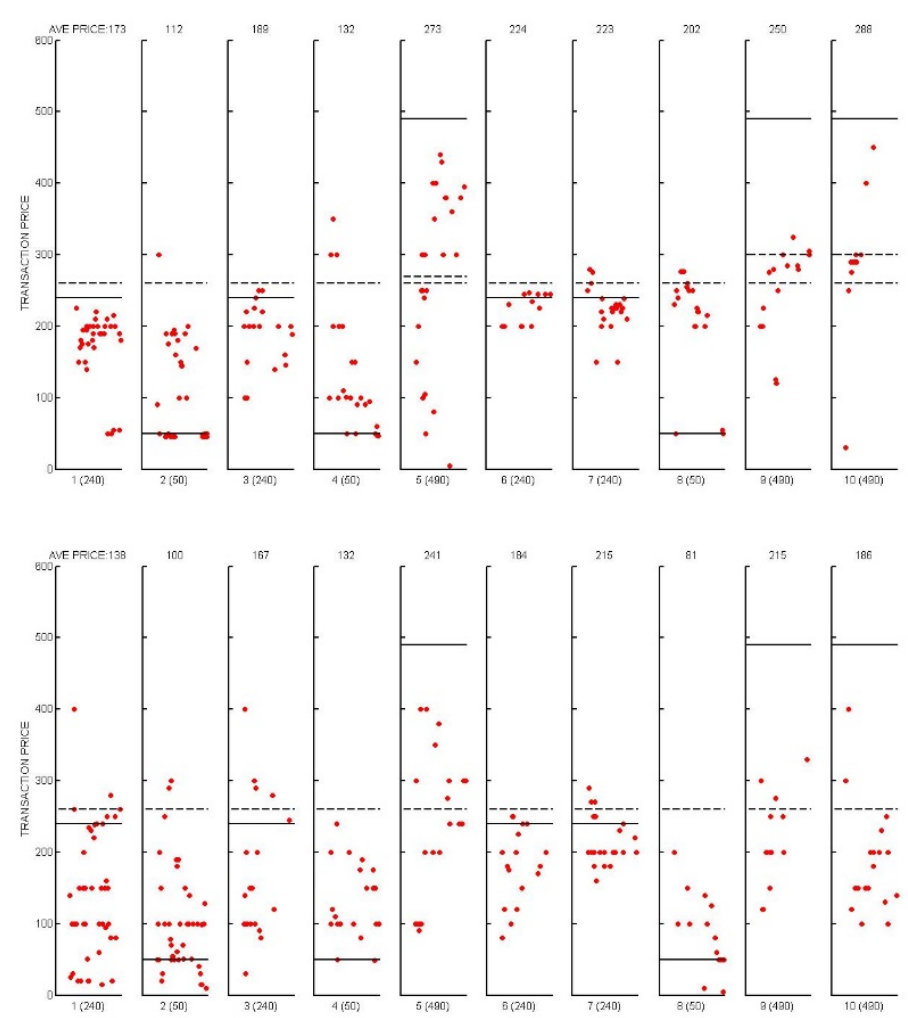
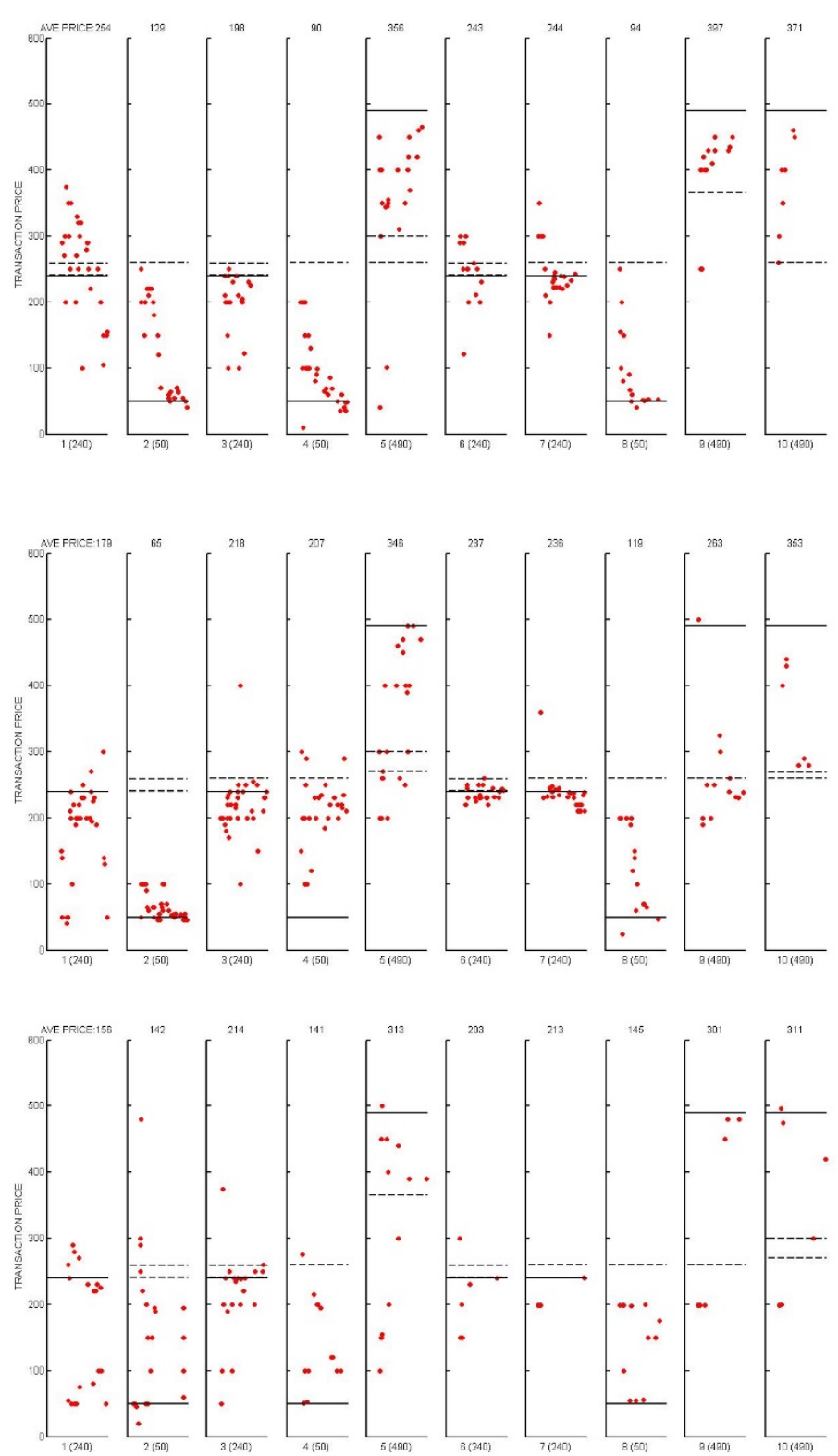
High Cost
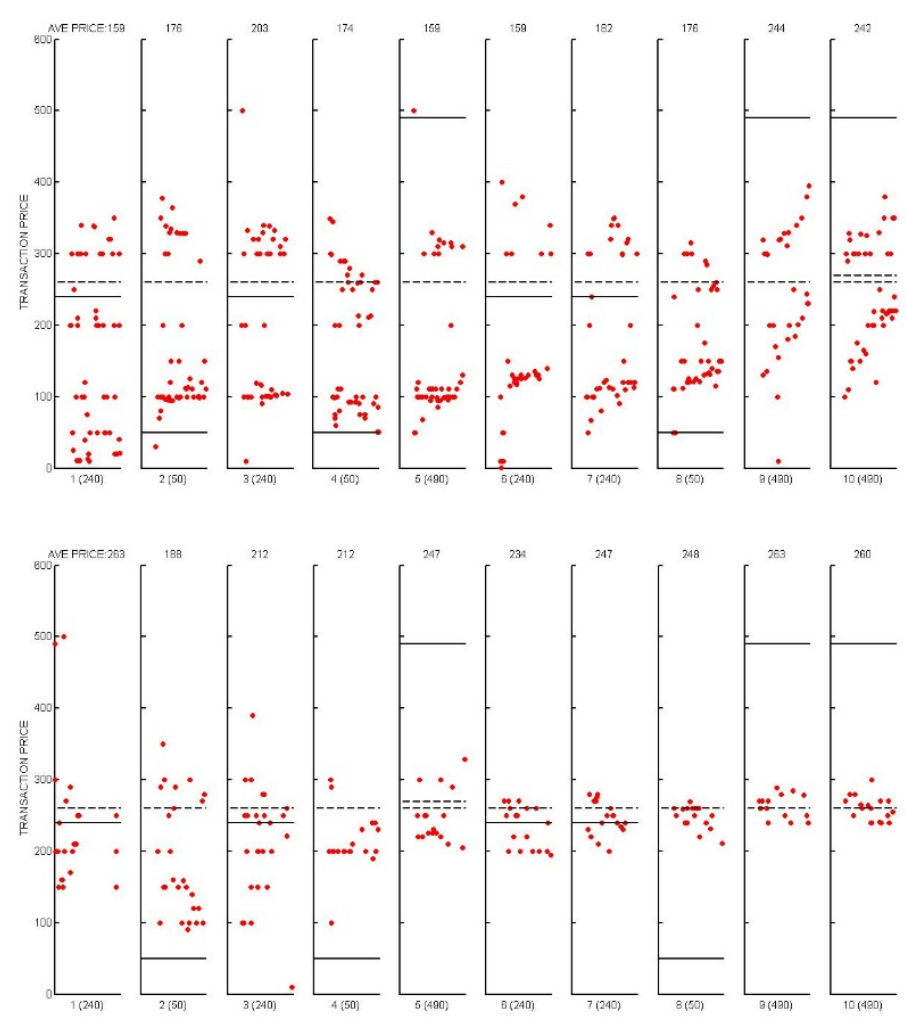
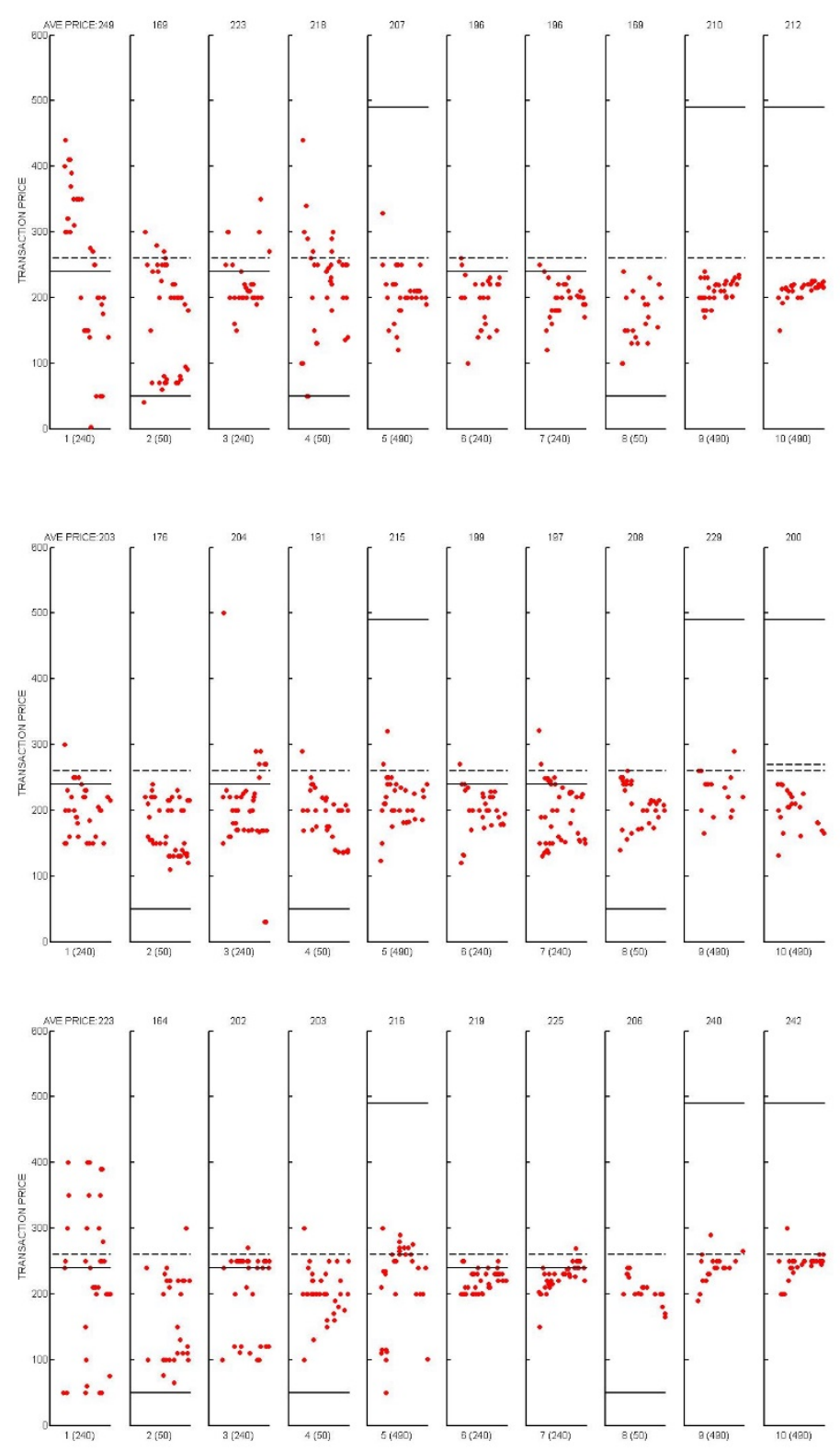


\section{Distribution}
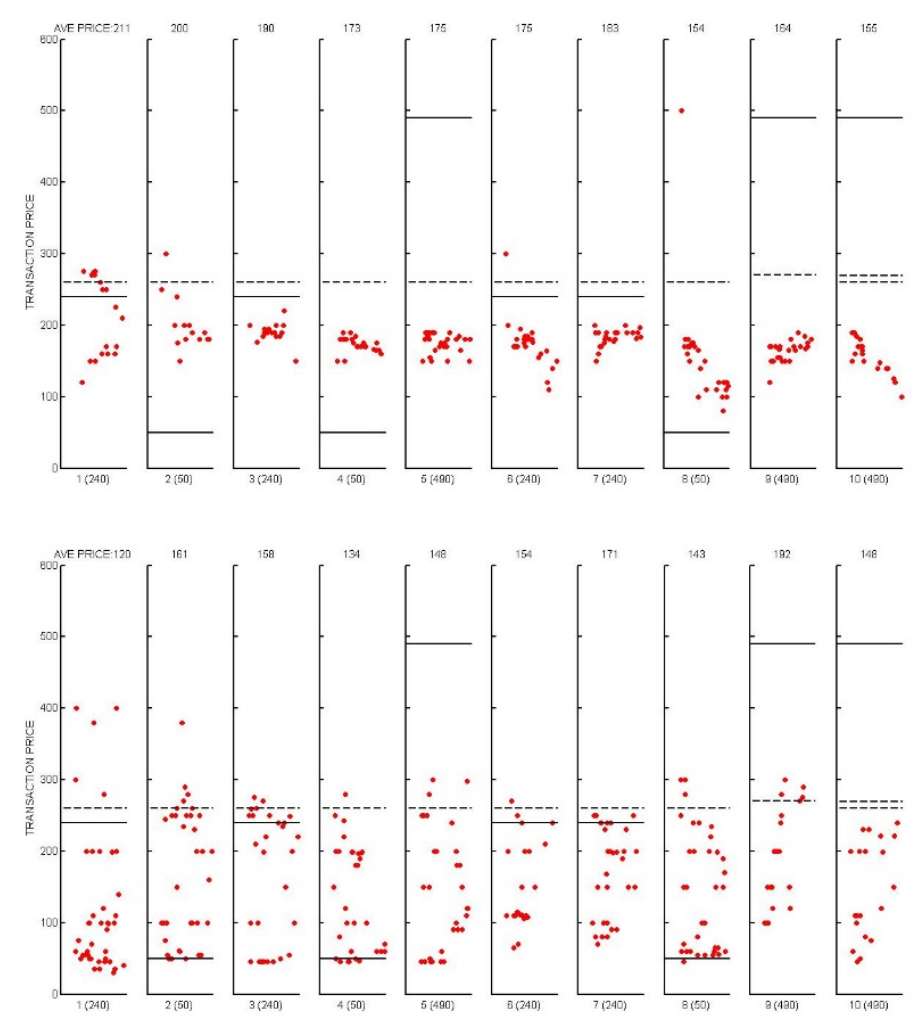
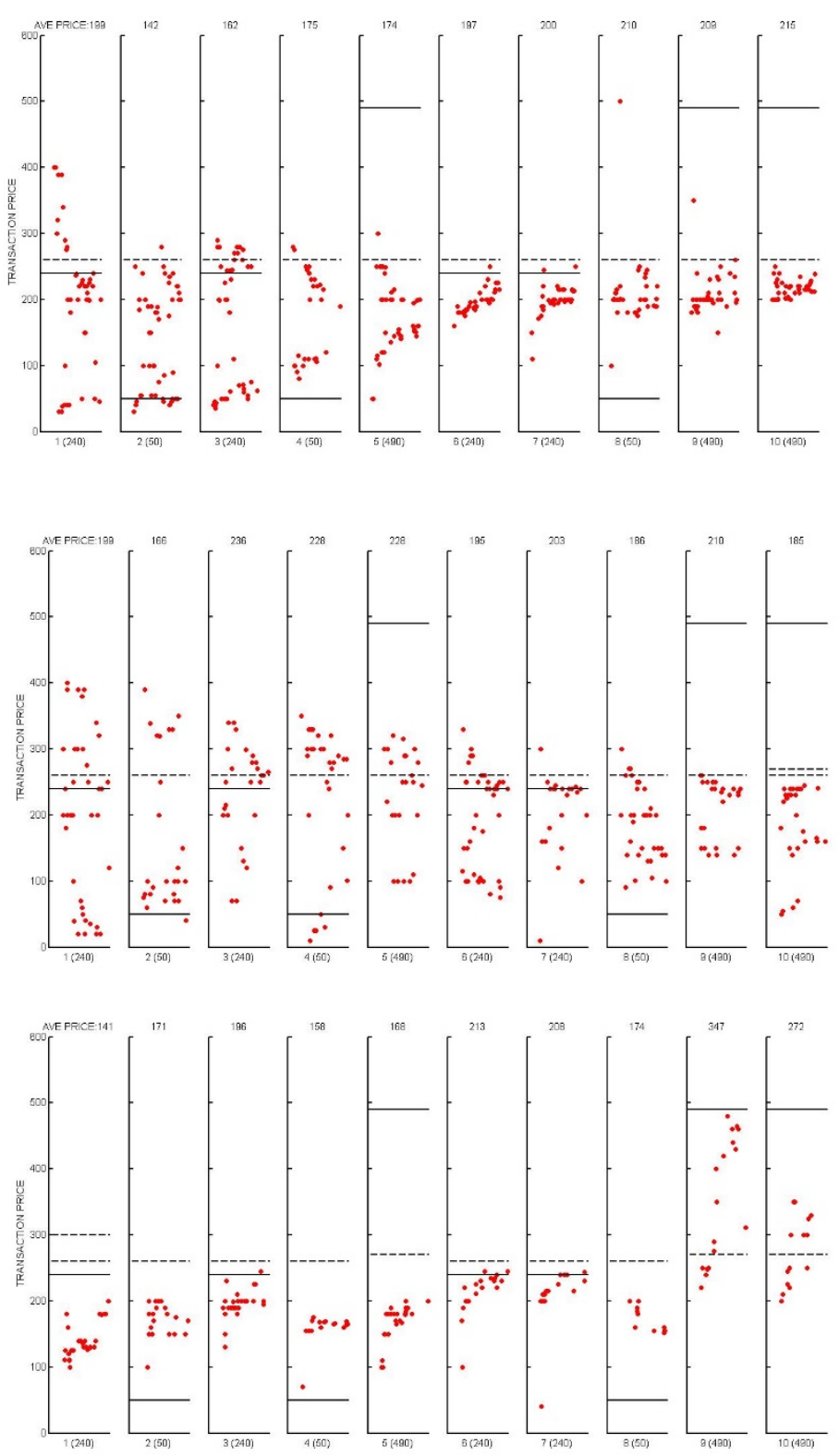


\section{No Information}
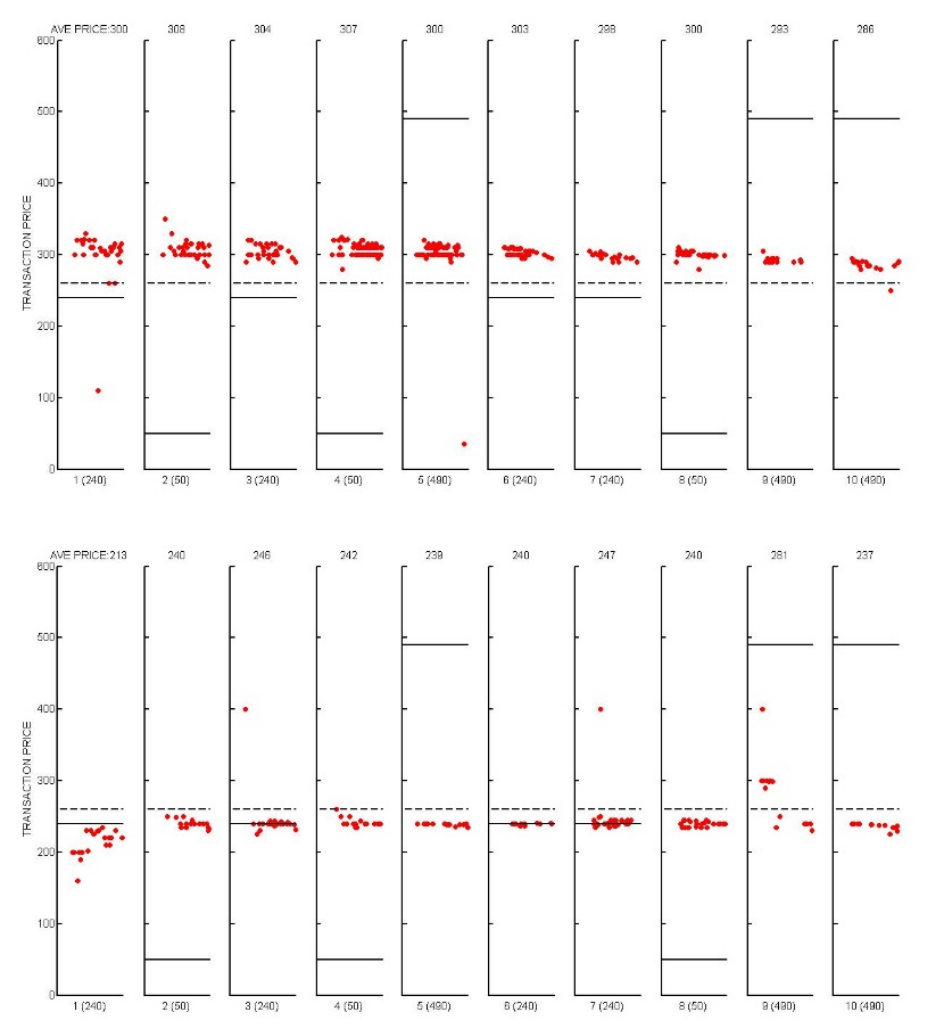
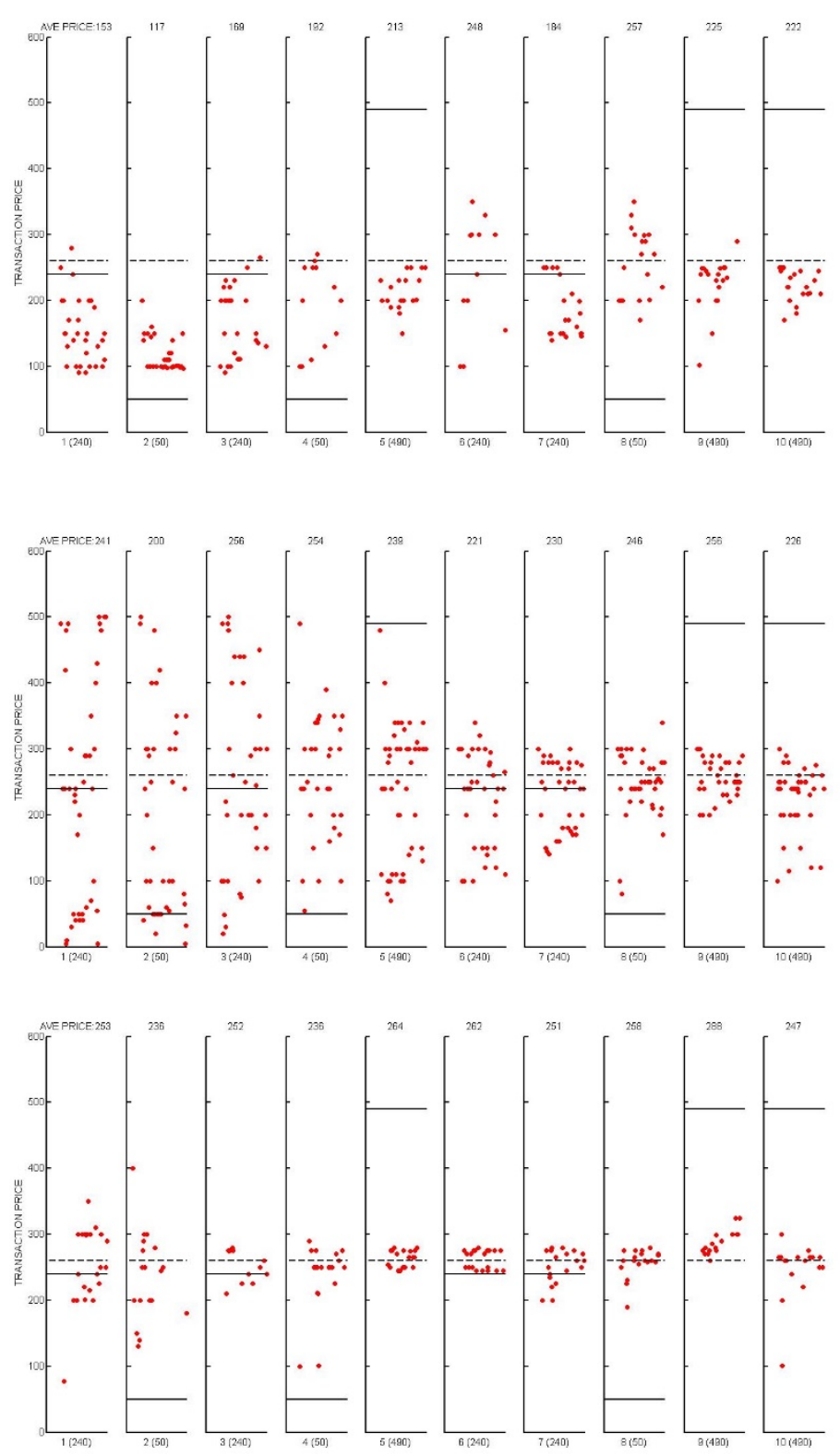


\section{Precise}
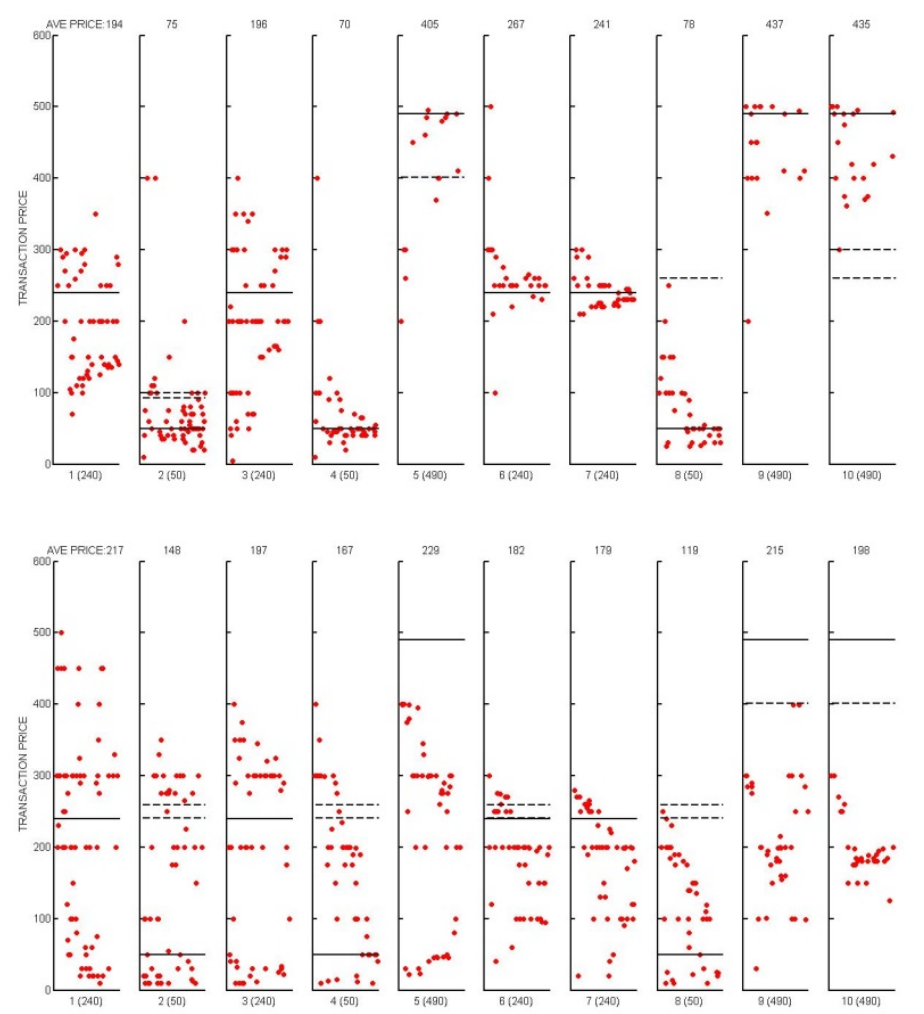
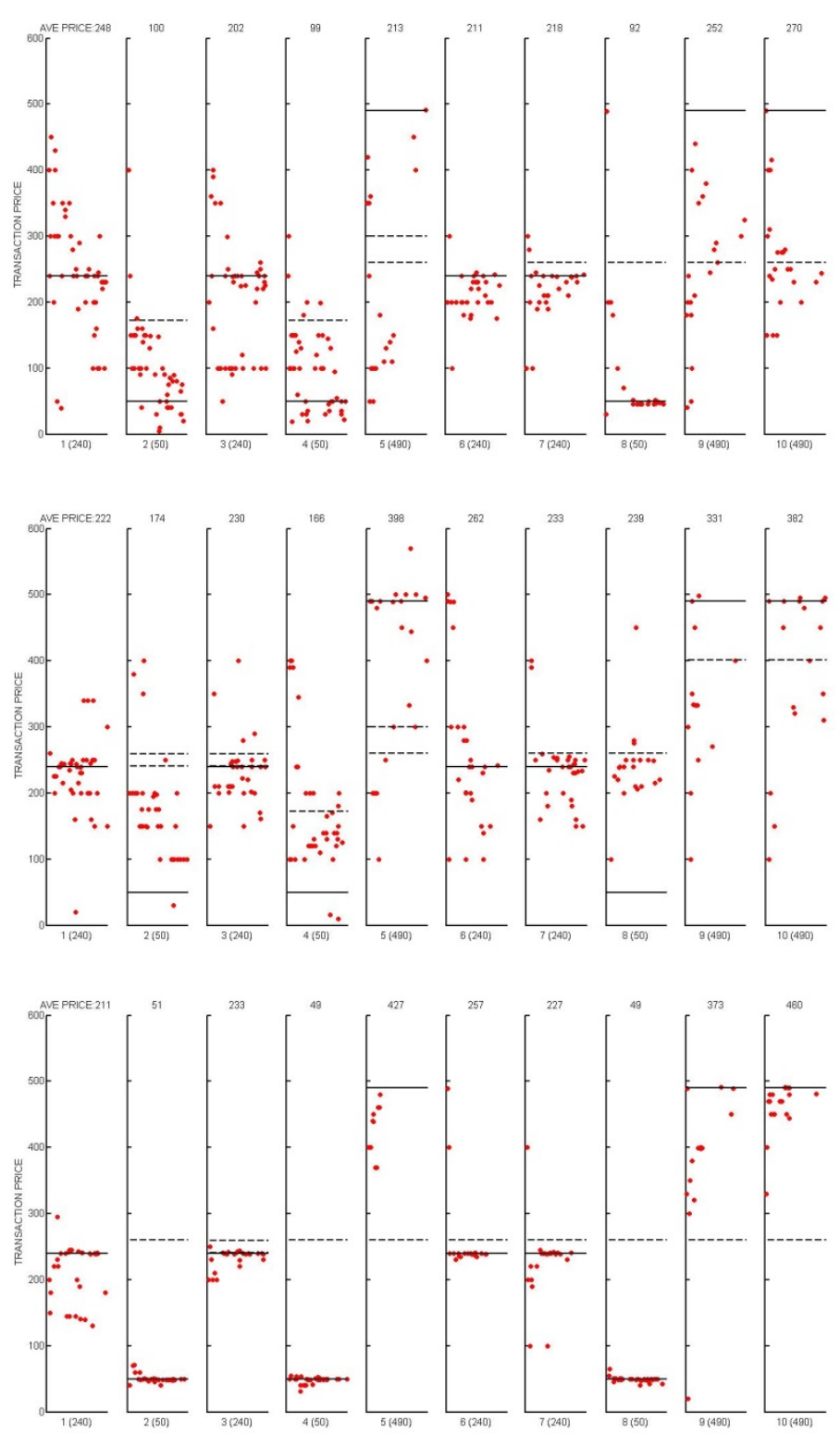


\section{Appendix C. Information on CRT and ToM Responses}

\section{CRT Instrument}

Taken from Frederick (2005):

(1) A bat and a ball cost $\$ 1.10$ in total. The bat costs a dollar more than the ball. How much does the ball cost? cents

[Correct answer: 5 cents; intuitive answer: 10 cents]

(2) If it takes 5 machines 5 minutes to make 5 widgets, how long would it take 100 machines to make 100 widgets? minutes

[Correct answer: 5 minutes; intuitive answer: 100 minutes]

(3) In a lake, there is a patch of lily pads. Every day, the patch doubles in size. If it takes 48 days for the patch to cover the entire lake, how long would it take for the patch to cover half of the lake? days

[Correct answer: 47 days; intuitive answer: 24 days]

Taken from Toplak et al. (2014):

(4) If John can drink one barrel of water in 6 days, and Mary can drink one barrel of water in 12 days, how long would it take them to drink one barrel of water together? days [correct answer: 4 days; intuitive answer: 9]

(5) Jerry received both the $15^{\text {th }}$ highest and the $15^{\text {th }}$ lowest mark in the class. How many students are in the class? students

[correct answer: 29 students; intuitive answer: 30]

(6) A man buys a pig for $\$ 60$, sells it for $\$ 70$, buys it back for $\$ 80$, and sells it finally for $\$ 90$. How much has he made? dollars [correct answer: \$20; intuitive answer: \$10]

(7) Simon decided to invest $\$ 8,000$ in the stock market one day early in 2008 . Six months after he invested, on July 17 , the stocks he had purchased were down $50 \%$. Fortunately for Simon, from July 17 to October 17 , the stocks he had purchased went up $75 \%$. At this point, Simon has: a. broken even in the stock market, b. is ahead of where he began, c. has lost money [correct answer: $c$; intuitive response: $b$ ] 
Table C.1 Distribution of CRT scores

\begin{tabular}{cc}
\hline \hline CRT score & \% of subjects \\
\hline 0 & 18.7 \\
1 & 23.3 \\
2 & 14.6 \\
3 & 16.7 \\
4 & 7.9 \\
5 & 7.9 \\
6 & 6.2 \\
7 & 4.6 \\
Mean & 2.43 \\
Std. Dev. & 2.04 \\
\hline
\end{tabular}

Theory of Mind Instrument

This is an example of one of the 36 eye gaze questions taken from Baron-Cohen (1997):

Fig. C Example of an eye gaze test question

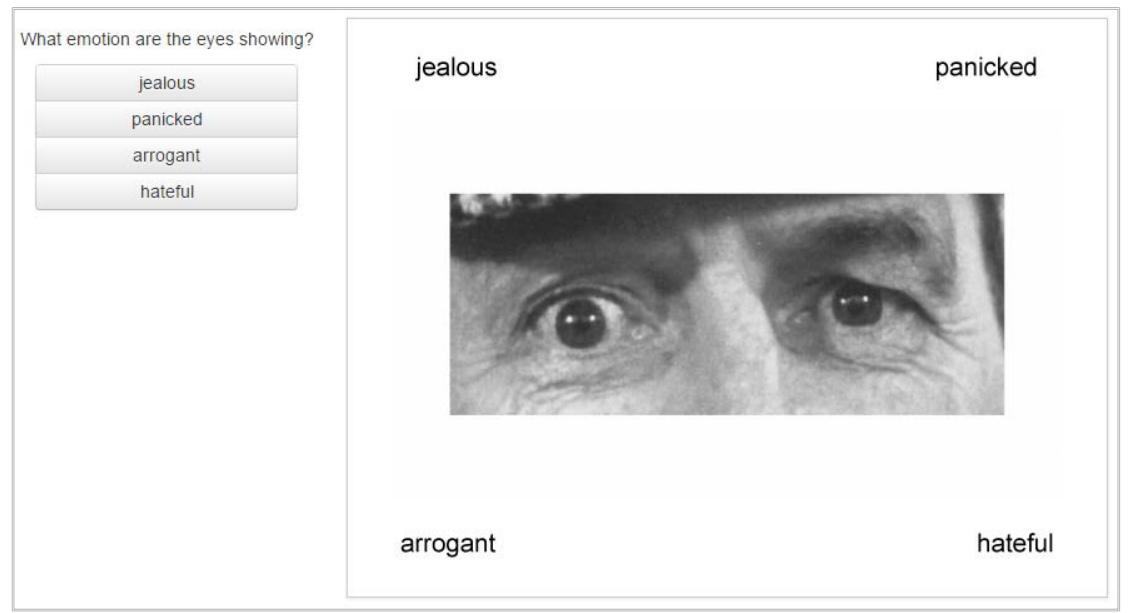

Table C.2 Distribution of ToM eye gaze test scores

\begin{tabular}{cccccccc|cc}
\hline \hline Eye gaze score & $0-9$ & $10-15$ & $16-20$ & $21-25$ & $26-30$ & $>30$ & Mean & Std. Dev. \\
\hline \% of subjects & 0.4 & 2.5 & 8 & 31 & 45 & 12.5 & 26 & 4.45 \\
\hline
\end{tabular}




\section{Appendix D. Relation between trader characteristics and clues purchased}

Table D Influence of Trader Characteristics on Number of Clues Purchased

\begin{tabular}{lc}
\hline \hline & $\begin{array}{c}\text { Number of clues } \\
\text { Purchased }\end{array}$ \\
& {$[1]$} \\
\hline Constant & $0.62^{* * *}$ \\
Male & $(0.08)$ \\
& 0.11 \\
Cognitive Reflection & $(0.08)$ \\
& 0.03 \\
Theory of Mind & $(0.04)$ \\
& $0.06^{*}$ \\
Period & $(0.03)$ \\
& $-0.01^{*}$ \\
Precise & $(0.01)$ \\
& $0.51^{* * *}$ \\
Full Information & $(0.12)$ \\
& $0.18^{* *}$ \\
Distribution & $(0.09)$ \\
& $-0.19^{* * *}$ \\
High Cost & $(0.07)$ \\
& $-0.22^{* * *}$ \\
\hline Observations & $(0.07)$ \\
\hline
\end{tabular}

$*, * *$, and $* * *$ denote significance at the $10 \%, 5 \%$, and $1 \%$ level respectively. This panel regression includes a random effect for each subject. Standard errors (reported in parentheses) are clustered at the session level. Data from the No Information treatment is excluded as these traders did not have the option to acquire clues. The number of observations is equal to the number of subjects (200) multiplied by the number of market periods (10). 